\title{
In Situ Growth, Structure, and Real-Time Chemical Reactivity of Well-Defined $\mathrm{CeO}_{\mathrm{x}}-\mathrm{Ru}(0001)$ Model Surfaces
}

\author{
David C. Grinter, ${ }^{1}$ Sanjaya D. Senanayake, ${ }^{1^{*}}$ and Jan Ingo Flege ${ }^{2^{*}}$ \\ ${ }^{1}$ Chemistry Department, Brookhaven National Laboratory, Upton, NY, USA \\ ${ }^{2}$ Institute of Solid State Physics, University of Bremen, Bremen, Germany \\ * Corresponding author: +49(0)421-218-62243, flege@ifp.uni-bremen.de, \\ +001(9)-631-344-4343, ssenanay@bnl.gov
}




\begin{abstract}
Ceria is an important material for chemical conversion processes in catalysis. Its intrinsic properties as a reducible oxide can be exploited to achieve catalytic selectivity and activity. However, numerous phenomenological characteristics of ceria remain unknown and its active nature is ever slowly being unraveled. Well defined models of ceria (111) are an important way to systematically study these properties and take advantage of new in situ methods that require pristine materials that allow for the interrogation of the most fundamental traits of this material. The ceria-Ru(0001) model is now the most well studied model surface with numerous aspects of its preparation, atomic structure and reactivity studied by several groups. The preparation of $\mathrm{CeO}_{\mathrm{x}}$ structures oriented with a (111) surface termination can be achieved through molecular beam deposition, facilitating the growth of well-defined nanostructures, microparticles, and films on the $\mathrm{Ru}(0001)$ surface. The growth mechanism exploits the epitaxial relationship between $\mathrm{CeO}_{\mathrm{x}}$ and $\mathrm{Ru}$ to form a carpet mode of well oriented layers of $\mathrm{O}-\mathrm{Ce}-\mathrm{O}$. These models can be studied to unravel the atomic structure and the oxidation state $\left(\mathrm{Ce}^{4+}\right.$ and $\left.\mathrm{Ce}^{3+}\right)$, as prepared and under redox conditions (reduction/oxidation) or with reaction using reactants (e.g. $\mathrm{H}_{2}$, methanol). Here, we present a discussion of these most recent observations pertaining to the growth mode, arrangement of atoms on the surface, characteristic chemical state, and redox chemistry of the $\mathrm{CeO}_{\mathrm{x}}-\mathrm{Ru}$ surface. With insights from these studies we propose new strategies to further unravel the chemistry of ceria.
\end{abstract}

\title{
Keywords
}

Ceria; Ru; model catalyst; reduction; oxidation; in situ characterization. 


\section{Introduction}

The utility of cerium oxide as a remarkable heterogeneous base catalyst material is now fully realized, with ample evidence in the literature for its versatile use in numerous chemical conversion processes including the water-gas shift (WGS) reaction [1, 2], CO oxidation [3], CO PROX [4], de-NOx (automotive exhausts) [5], $\mathrm{CO}_{2}$ hydrogenation [6], olefin hydrogenation [7], methane activation [8], alcohol steam reforming [9], and others [10]. In all cases, the intrinsic phenomenological properties of ceria allow reactions to be steered (selectivity), stabilized, and performance enhanced (activity). Our understanding of how such active traits manifest their role in reactions is ever evolving, enriched with the development of new analytical tools for in situ analysis. We are now entering a phase of research and development where we are starting to learn about the dynamic nature of the properties of ceria that prevail under reaction conditions and how we can exploit them to achieve greater improvements in catalytic chemistry.

The primary catalytic use of ceria is as a reducible oxide support, where it has been commonly used as a substrate to anchor, activate, and promote metals or other oxides. However, the primitive perception that this oxide (and others) is an inert support and unlikely to activate reactions has evolved to affirm important support effects, including atomic and defect geometry [11], electronic [12] and ligand effects [13, 14] that were not realized before. Furthermore, the oxides used as nano-catalysts [15] or as mixed oxides [16, 17] have allowed their exploitation as the active agent in several reactions. The key factors that make ceria important remain its facile reducibility, high oxygen storage capacity (OSC), simply interchangeable oxidation states $\left(\mathrm{Ce}^{4+}, \mathrm{Ce}^{3+}\right)$, electron rich centers $(4 \mathrm{f})$ and stable crystal structure. The fundamental investigations into the atomic structure, physical and chemical properties, surface chemistry, and electronic structure of ceria have allowed for a more complete understanding of challenging observations made at reaction conditions.

To date, a large body of work has been devoted to well-defined cerium oxide surfaces supported on a variety of metal substrates, of which the $\mathrm{CeO}_{\mathrm{x}}(111)-\mathrm{Ru}(0001)$ model has been devoted considerable attention. This system, initially prepared as a continuous $\mathrm{CeO}_{\mathrm{x}}$ film [1820], has facilitated experimental investigations of the atomic structure (scanning tunneling microscopy (STM)), chemical state (X-ray photoelectron spectroscopy (XPS)), and surface chemistry upon reaction with numerous reactants [21-24]. In addition, we now have recipes to synthesize well defined $\mathrm{CeO}_{\mathrm{x}}(111)$ nanostructures and micron-sized particles [25-27] as well as surfaces with careful control of cation densities $\left(\mathrm{Ce}^{4+} / \mathrm{Ce}^{3+}\right)$ and $\mathrm{Ce} / \mathrm{O}$ stoichiometry on $\mathrm{Ru}(0001)$ [28]. This has greatly expanded the use of this particular system to further 
interrogate fundamental catalytic properties [20, 29, 30], e.g., as a well-defined oxide support for post-grown metallic nanoparticles [31-34]. We have exploited this particularly to study the dynamic properties of ceria by using new in situ methods such as Low Energy Electron Microscopy (LEEM) and X-ray Photoemission Electron Microscopy (XPEEM).

In this perspective article, we provide a coherent overview of the versatile $\mathrm{CeO}_{\mathrm{x}}-\mathrm{Ru}(0001)$ system by covering essential aspects of the prevailing preparation methodology, the typical growth mechanism, atomic surface structure and its chemical state after preparation. In doing so, we also highlight the importance of the catalyst surface structure to effect the chemical reactivity of ceria in redox reactions. Finally, we discuss the prospects of applying real time in situ methods (LEEM/XPEEM) for probing chemical reactivity in ceria based model catalysts.

\section{Growth of $\mathrm{CeO}_{\mathrm{x}}$ on $\mathrm{Ru}(0001)$}

Low Energy Electron Microscopy (LEEM) is particularly well suited to study the growth of $\mathrm{CeOx}$ on $\mathrm{Ru}(0001)$ surfaces, due to its high resolution, large temperature range, and rapid image acquisition rate [35]. As a full-field diffractive imaging technique with full ultrahighvacuum compatibility [36, 37], real-time monitoring of surface processes may readily be performed both in real and reciprocal space, effectively spanning the whole range from the atomic scale (via diffraction mode) to the nanometer and micrometer scale. Furthermore, with an improved understanding of the process of contrast formation in the microscope [38-41] a quantitative in situ assessment of surface structure as well as thermodynamically and kinetically driven surface phenomena is viable; moreover, the increasing availability of LEEM instruments equipped with energy filters at synchrotron radiation sources offers the attractive prospect of complementary characterization by spatially-resolved X-ray absorption spectroscopy (XAS) and photoemission electron microscopy (XPEEM) [42] techniques. Three-dimensional information on crystallographic structure and molecular adsorption sites may be obtained by analyzing the dependence of the local electron reflectivity on electron kinetic energy, the so-called intensity-voltage $(I(V))$ curve [43]. This approach currently provides the highest spatial resolution and may be expected to become even more powerful with the advent of aberration-corrected microscopes [44] that have pushed the achievable lateral resolution down to less than $2 \mathrm{~nm}$. In the following, we provide a comprehensive overview of the novel insights into the ceria-ruthenium system that have been obtained in previous studies by applying this combined LEEM/PEEM technique.

LEEM images (see the supplemental material for a real-time growth movie) were recorded by Kaemena et al. [26] for the growth of ceria on $\mathrm{Ru}(0001)$ as the amount of deposited ceria 
increased and at different substrate temperatures as displayed in Figure 1: $\left(575^{\circ} \mathrm{C}\right.$, (a)-(c); $800{ }^{\circ} \mathrm{C}$, (d)-(f); $900{ }^{\circ} \mathrm{C}$, (g)-(i); $1000{ }^{\circ} \mathrm{C}$, (j)-(l)). Initially only the $\mathrm{Ru}(0001)$ atomic steps (thin dark lines) and step bunches (broad dark lines) appear, with atomically flat terraces. Nucleation commences visibly at low coverages of 0.02-0.05 ML (second series), and higher coverages 0.61 and $1.83 \mathrm{ML}$ (third series).

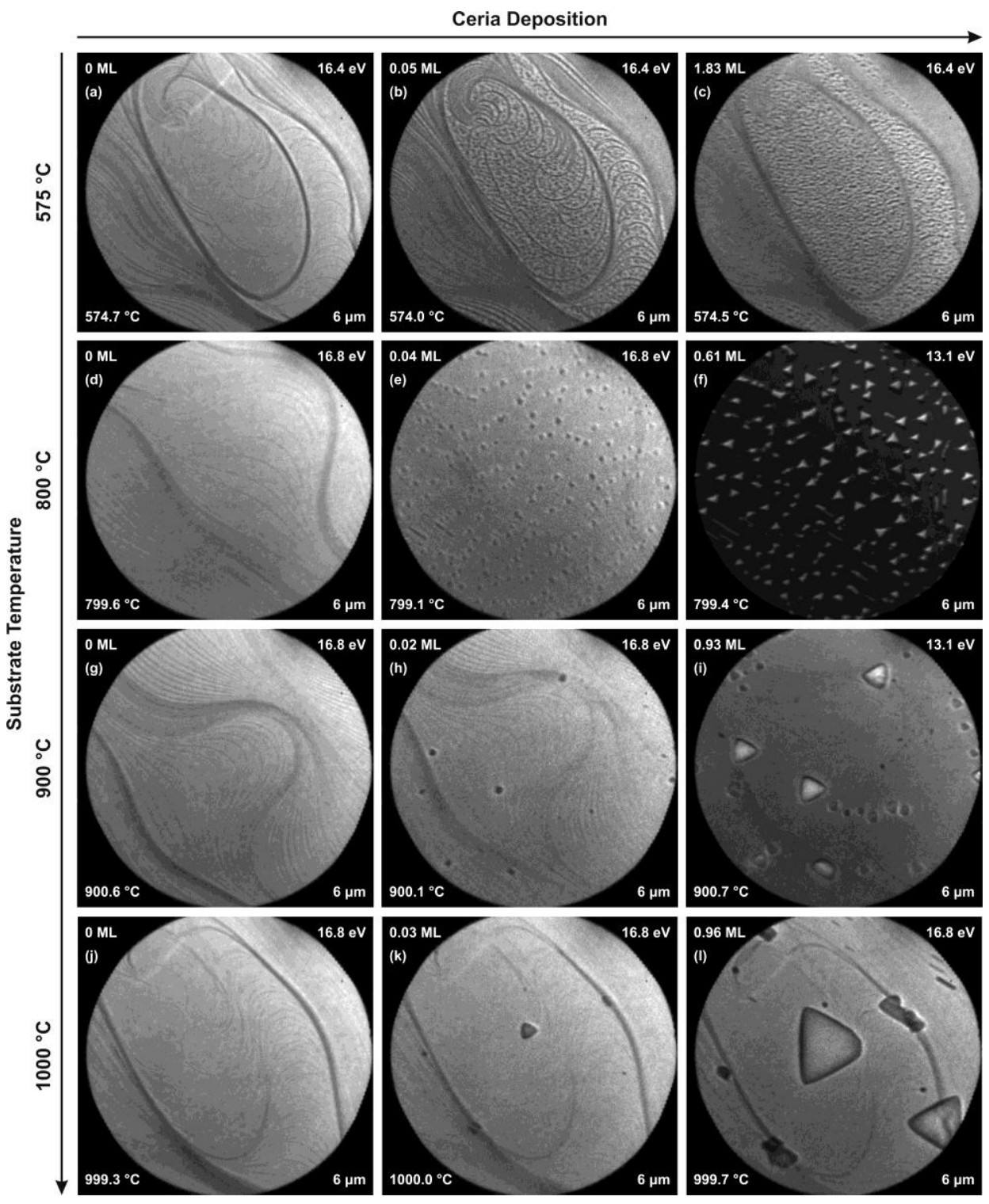

Figure 1. Growth of ceria on $\mathrm{Ru}(0001)$ at different substrate temperatures and stages of growth (increasing deposited amount of ceria). From left to right: advancing stage of growth. From top to bottom: increasing substrate temperature. The ceria island size increases with substrate temperature while the ceria island density decreases. The different contrast in panels (f) and (i) compared to the other panels is due to a different electron kinetic energy. The 
cerium deposition rate is the same in all cases. Reprinted with permission from [26]. Copyright 2013 American Chemical Society.

At $575{ }^{\circ} \mathrm{C}$ very small ceria islands nucleate at high density, and continued growth results in the formation of a closed ceria film. With increased temperature, the island size increases while the island density decreases; also, with increased temperature the islands adopt an almost perfect triangular shape. The nucleation density is influenced by the growth temperature and is independent on the amount of ceria, in accordance with basic nucleation theory [45]. Continued deposition of ceria only increases the size of the ceria islands and does not affect the nucleation density, again implying that it is mainly controlled by surface kinetics (see section 3). Ceria grown at $900{ }^{\circ} \mathrm{C}$ at $4.5 \mathrm{ML}$ of ceria shows the clear growth of large micrometer-sized particles (Figure 2, also see movie in Supplementary Material) [26]. These large islands appear with an almost perfect triangular shape, reflecting the threefold symmetry of the fluorite lattice, and preferentially develop on substrate terraces, while the island density is strongly increased at step bunches, which are discernible as bright "bands" in the large-scale overview image (Figure 2b). This decoration effect is due to an enhanced oxygen uptake in the stepped regions of the Ru(0001) crystal [46]. Hence, in this temperature regime the island nucleation density and their shape are determined both by the growth temperature and the surface morphology of the substrate (see section 5).
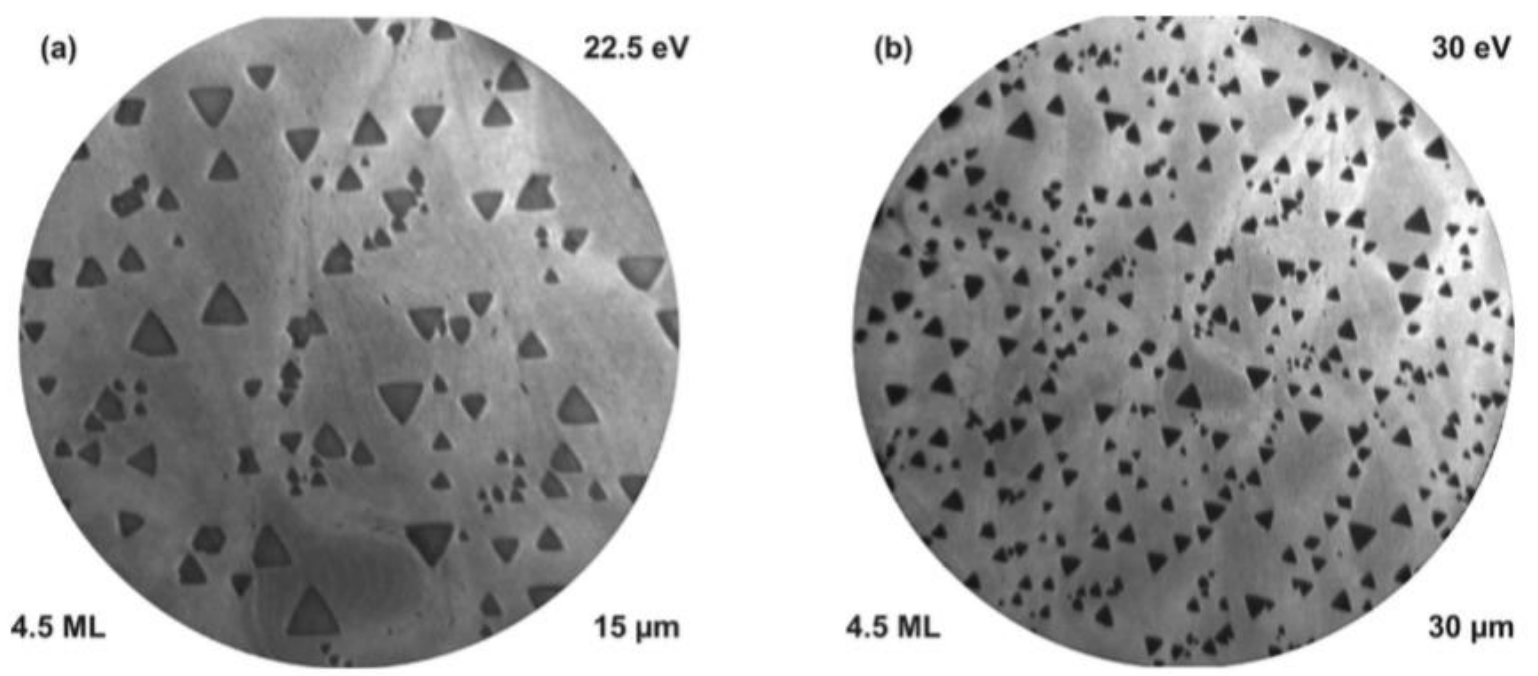

Figure 2. Different fields of view of ceria grown on $\mathrm{Ru}(0001)$ at a $900^{\circ} \mathrm{C}$ substrate temperature and an oxygen partial pressure of $5 \times 10^{-7}$ Torr showing the nucleation behavior of 
the islands on substrate terraces and step bunches. (a) FOV $=15 \mu \mathrm{m}$ and (b) FOV $=30 \mu \mathrm{m}$. Ceria islands with an almost perfect triangular shape preferentially develop on substrate terraces while the island density is strongly increased at step bunches. Reprinted with permission from [26]. Copyright 2013 American Chemical Society.

The geometric structure of the ceria islands was determined by Flege et al. [25] using the low energy electron diffraction (LEED) pattern as shown in Figure 3. The outer hexagonal ring consists of 6 sharp diffraction spots, which mark the first-order Bragg reflections of the $\mathrm{Ru}(0001)$ substrate. Furthermore, relatively weak half-order spots are discernible corresponding to the three-domain $(2 \times 1)-\mathrm{O}$ adsorbate superstructure. In addition to these, the LEED pattern shows an inner hexagonal ring of ceria related $\mathrm{p}(1.4 \times 1.4)$ superstructure spots, which result from the (111)-oriented fluorite crystal lattice [18, 19]. These diffraction spots are found along the main-symmetry and lower symmetry directions of the substrate. Since these oxide patches preferentially lie along the same directions as the substrate integer order maxima, there is a well-defined two-dimensional registry of the ceria islands with respect to the underlying substrate lattice. Furthermore, since the fluorite structure only exhibits a threefold rotation axis, this configuration gives rise to the occurrence of rotational domains of ceria. Employing a diffracted beam with non-vanishing in-plane momentum transfer for socalled dark-field imaging, these rotational domains can clearly be mapped in real space (Figure 3c), also allowing a determination of the amount of ceria minority particles whose inplane lattice vectors are not aligned in parallel to the substrate.
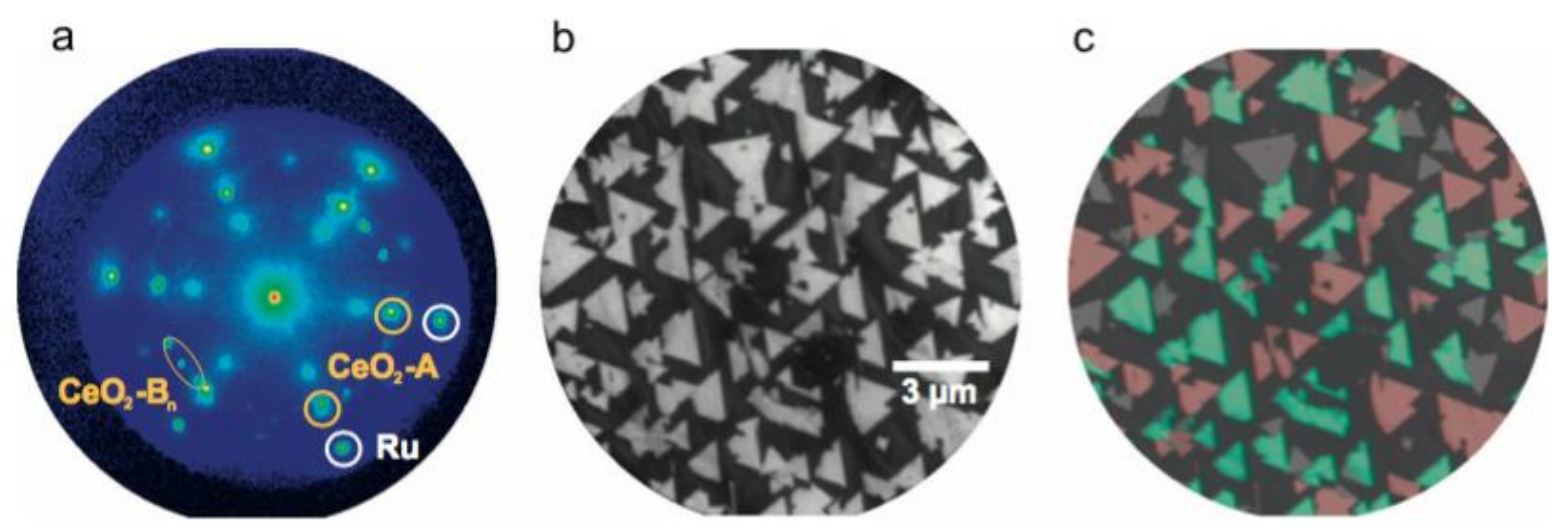

Figure 3. (a) Low-energy electron diffraction pattern acquired after cerium oxide growth $(\mathrm{E}=40 \mathrm{eV})$. The integer reflections of $\mathrm{Ru}(0001), \mathrm{CeO}_{2}(111)-\mathrm{A}$, and $\mathrm{CeO}_{2}(111)-\mathrm{B}$ are labeled. (b) Bright-field (BF) LEEM image, and (c) composite image consisting of one BF image (displayed in (b)) and two dark-field LEEM images recorded using the (10) reflections of 
A/A'-type cerium oxide as indicated in (a). The gray domains of the BF image that do not coincide with cerium oxide islands in the DF images highlight the azimuthally rotated $\mathrm{B}_{\mathrm{n}}$-type cerium oxide domains. Reprinted from [25], with permission from Elsevier.

After establishing the basic growth characteristics and the ceria island geometry with respect to the ruthenium support, we now turn to the morphology and crystallographic structure of the ceria particles.

\section{Morphology and Atomic Structure}

The ceria island morphology and atomic structure have been investigated by atomic force microscopy (AFM) (Figure 4) [26] and STM (Figure 5) [47]. Figure 4a shows an AFM image of a ceria model catalyst prepared at $800{ }^{\circ} \mathrm{C}$ and at an oxygen partial pressure of $5 \times 10^{-7}$ Torr (ceria coverage $\sim 1 \mathrm{ML}$ ), comparable to the LEEM image displayed in Figure 1f. The perfectly triangular islands are approximately $3 \mathrm{~nm}$ tall with very sharp edges (See line scans in Figure 4b). The islands exhibit large, flat terraces and step edges that are significantly influenced by the step edges of the $\mathrm{Ru}$ substrate (also see section 5). The ceria island triangles are not perfectly equilateral with two sides of the same lengths (isosceles) while the remaining side is shorter. This may indicate a non-negligible influence of the substrate even at this high growth temperature, where the morphology and shape can be expected to essentially represent the intrinsic structural properties of the ceria particles. 

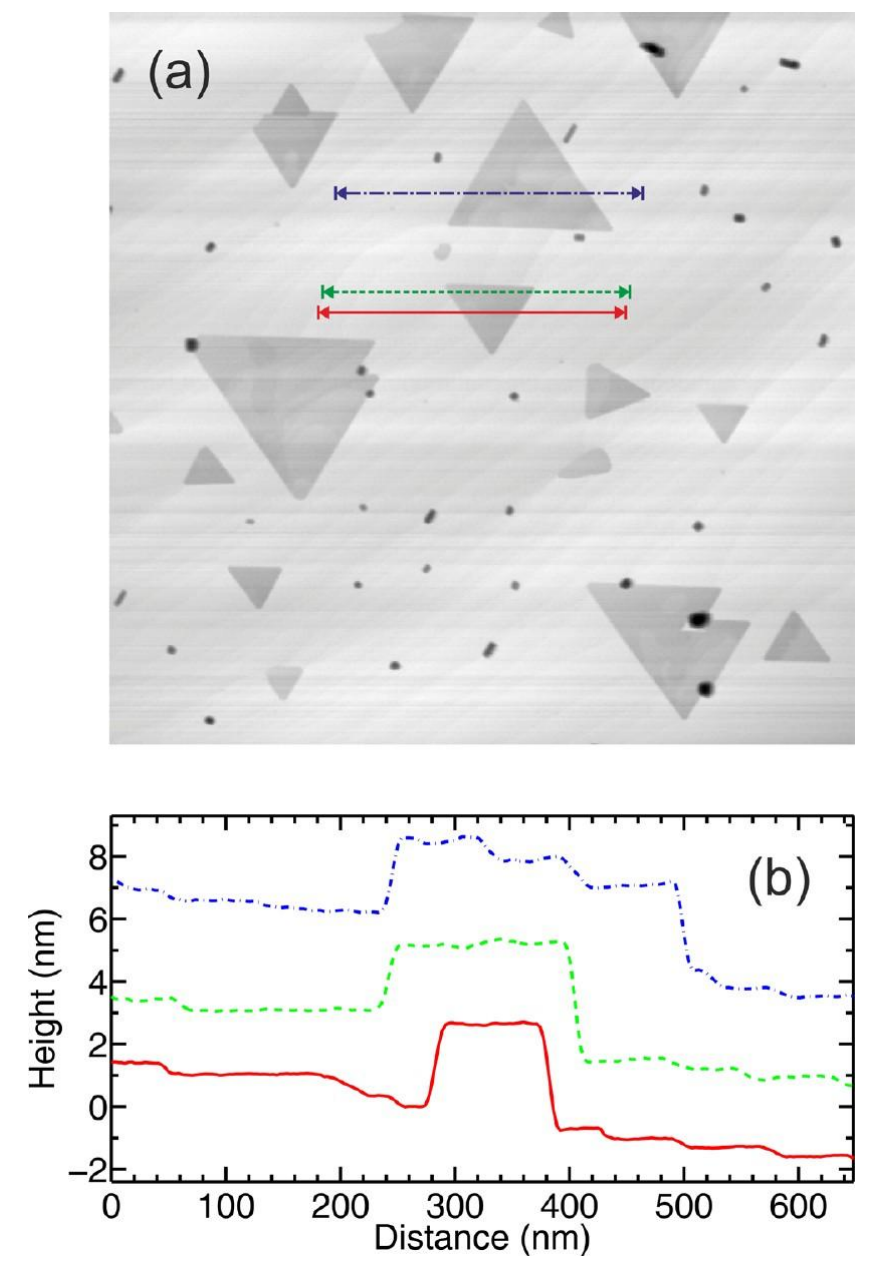

Figure 4. (a) $1.5 \times 1.5 \mu \mathrm{m}^{2}$ ex situ AFM image of fully oxidized ceria islands on $\mathrm{Ru}(0001)$ with a coverage of $1 \mathrm{ML}$ grown at a substrate temperature of $800{ }^{\circ} \mathrm{C}$ and an oxygen partial pressure of $5 \times 10^{-7}$ Torr. (b) Respective line scans showing approximately $3 \mathrm{~nm}$ tall ceria islands with sharp edges and the terraces and steps of the $\mathrm{Ru}(0001)$ substrate surface. For presentation purposes, panels (a) and (b) exhibit different background subtractions and the line scans in panel (b) are shifted in the vertical direction. Reprinted with permission from [26]. Copyright 2013 American Chemical Society.

While the atomic structure of the ceria islands cannot be addressed by ex situ AFM under ambient conditions, they provide easy access to the "missing" third dimension in LEEM; also, they make an excellent bridge between the mesoscale LEEM and the nanoscale STM images that may additionally provide atomically resolved insights into the geometric and electronic surface structure of the ceria particles, including the nature of the defects. 

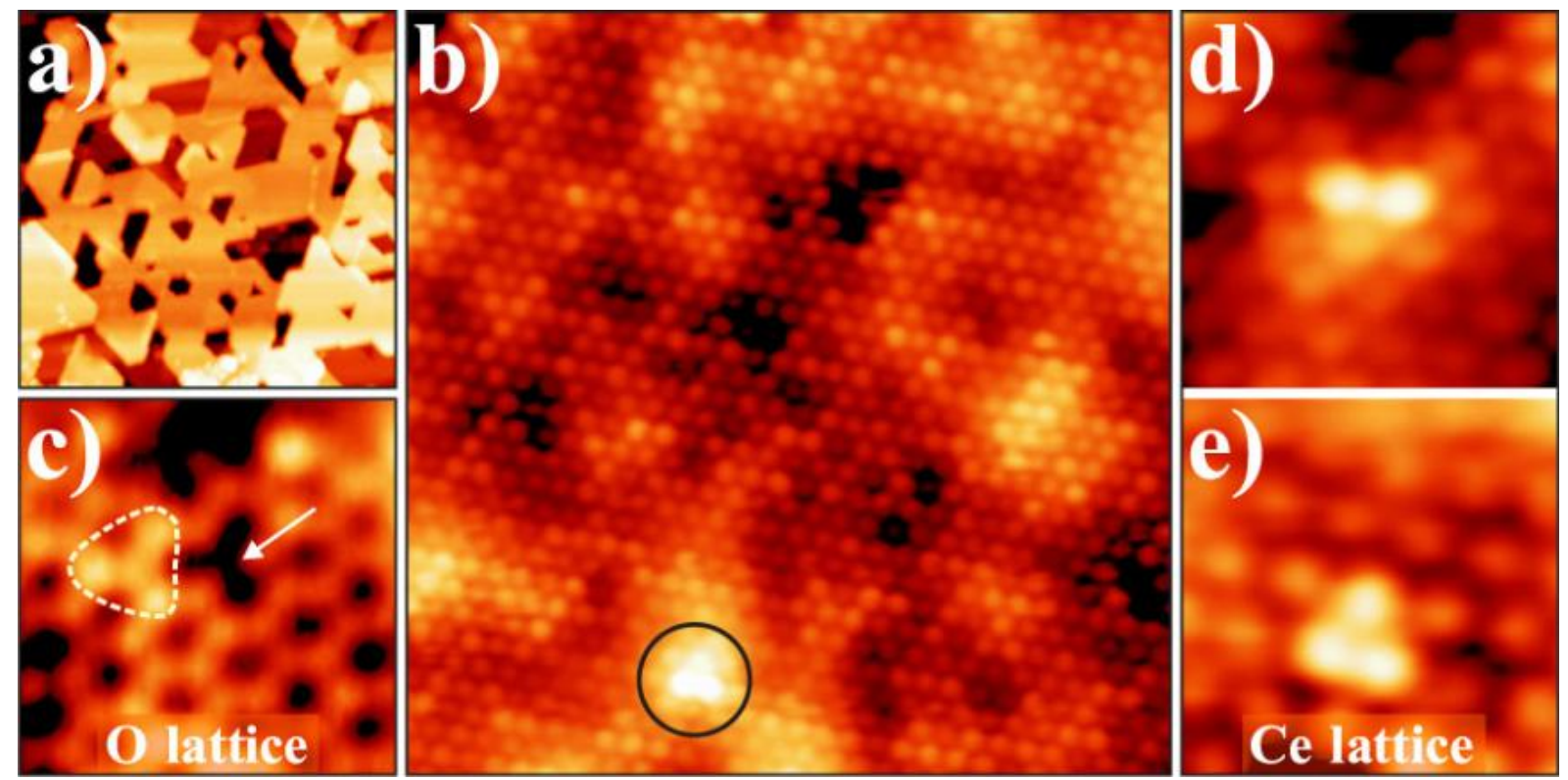

Figure. 5 (a) STM image of a 5 trilayer thick $\mathrm{CeO}_{2}$ film grown on $\mathrm{Ru}(0001)(3.1 \mathrm{~V}, 100 \mathrm{x}$ $100 \mathrm{~nm}^{2}$ ) (b) Atomically resolved image showing the Ce sublattice $\left(1.2 \mathrm{~V}, 12 \times 12 \mathrm{~nm}^{2}\right)$. The protrusion in the lower part is assigned to a single O vacancy. (d),(e) Similar defects imaged with a tip configuration that is sensitive to the Ce lattice $\left(1.2 \mathrm{~V}, 2.4 \times 2.4 \mathrm{~nm}^{2}\right)$ and (c) to the $\mathrm{O}$ lattice $(-2.2 \mathrm{~V})$. The arrow in (c) marks a surface $\mathrm{O}$ vacancy, while the triangle denotes a subsurface defect characterized by three protruding $\mathrm{O}$ ions. Reprinted with permission from [40]. Copyright 2011 by the American Physical Society.

A primary strength of the STM is the ability to probe the atomic structure of the surface of the ceria films, including individual point defects and other reactive sites, and has been demonstrated for $\mathrm{CeO}_{2}$ (111) films prepared on a number of metallic substrates [48, 49]. The results displayed in Figure 5 were obtained by Jerratsch et al. in an ultrahigh vacuum STM operated at $10 \mathrm{~K}$ on a $1.5 \mathrm{~nm}$ (5 trilayer) thick ceria film on $\mathrm{Ru}(0001)$ [40]. This was prepared by depositing $\mathrm{Ce}$ onto a sputtered and annealed $\mathrm{Ru}(0001)$ surface in $5 \times 10^{-6} \mathrm{mbar} \mathrm{O}_{2}$, whereby half of the material was dosed at $100 \mathrm{~K}$ and half at $450 \mathrm{~K}$. After annealing to $1000 \mathrm{~K}$ in $\mathrm{O}_{2}$, the film displays a sharp $\mathrm{p}(1.4 \times 1.4)$ LEED pattern that is characteristic for the $\mathrm{CeO}_{2}(111)$ surface (cf. Figure 3a) and bare areas of the substrate are visible between the ceria (Figure 5a). Atomically resolved STM measurements are mainly obtained at positive sample bias (unoccupied states), where the $\mathrm{Ce}^{4+}$ cations are responsible for the contrast (Figure $5 \mathrm{~b}$ ). At negative bias, the filled $\mathrm{O} 2 \mathrm{p}$ states govern the contrast (Figure 5c); however, atomic resolution is more difficult to obtain. In both cases, the observed atom periodicity of $4.0 \AA$ is consistent with the $\mathrm{CeO}_{2}$ lattice constant of $3.83 \AA$. As the ceria films were prepared in an 
excess of $\mathrm{O}_{2}$ they exhibit only a small defect concentration. Oxygen vacancies were therefore generated by exposure of the film to $50 \mathrm{eV}$ electrons $(1 \mathrm{mC}$ dose $)$ at $100 \mathrm{~K}$. At positive sample bias (empty states), the surface oxygen vacancies appear as paired and tripled protrusions of $\sim 0.4 \AA$ height, which mark the $\mathrm{Ce}^{3+}$ ions around the vacancy (Figures $5 \mathrm{~d}$ and 5 e). When an oxygen vacancy is formed, excess electrons remain in the surface resulting in two $\mathrm{Ce}^{4+}$ cations becoming reduced to $\mathrm{Ce}^{3+}$. From the appearance in STM images (Figure 5d and $5 \mathrm{e}$ ), there is some variation in the localization of this excess charge although the precise position is still not clear, even with the evidence provided by scanning tunneling spectroscopy and DFT simulations. These $\mathrm{Ce}^{3+}$ sites do appear to play an important role in the nucleation of $\mathrm{Au}$ atoms on top of the ceria, and as such are of much interest for future studies of reactivity and support of metal nanoparticles [50]. At negative sample bias, the oxygen vacancies appear as dark atom-sized depressions, confirming their identity as a surface $\mathrm{O}$ vacancy (Figure 5c, arrow) $[11,51]$. In addition to these, subsurface vacancies that appear as three protruding maxima at negative bias are occasionally observed (Figure 5c, dashed triangle).

\section{Thermodynamic and Kinetic Effects on Growth}

The effect of temperature on the growth process was carefully studied, with preparation of ceria islands at different temperatures. Figure 6 shows this in a series of images with triangular shaped islands of ceria forming on the $\mathrm{Ru}(0001)$ substrate at temperatures between $970 \mathrm{~K}$ and $1270 \mathrm{~K}$. This growth follows an Arrhenius-like dependence of island density on temperature. It is possible to obtain an activation energy of $E_{\mathrm{A}}=2.03 \pm 0.08 \mathrm{eV}$ from this trend [26]. 


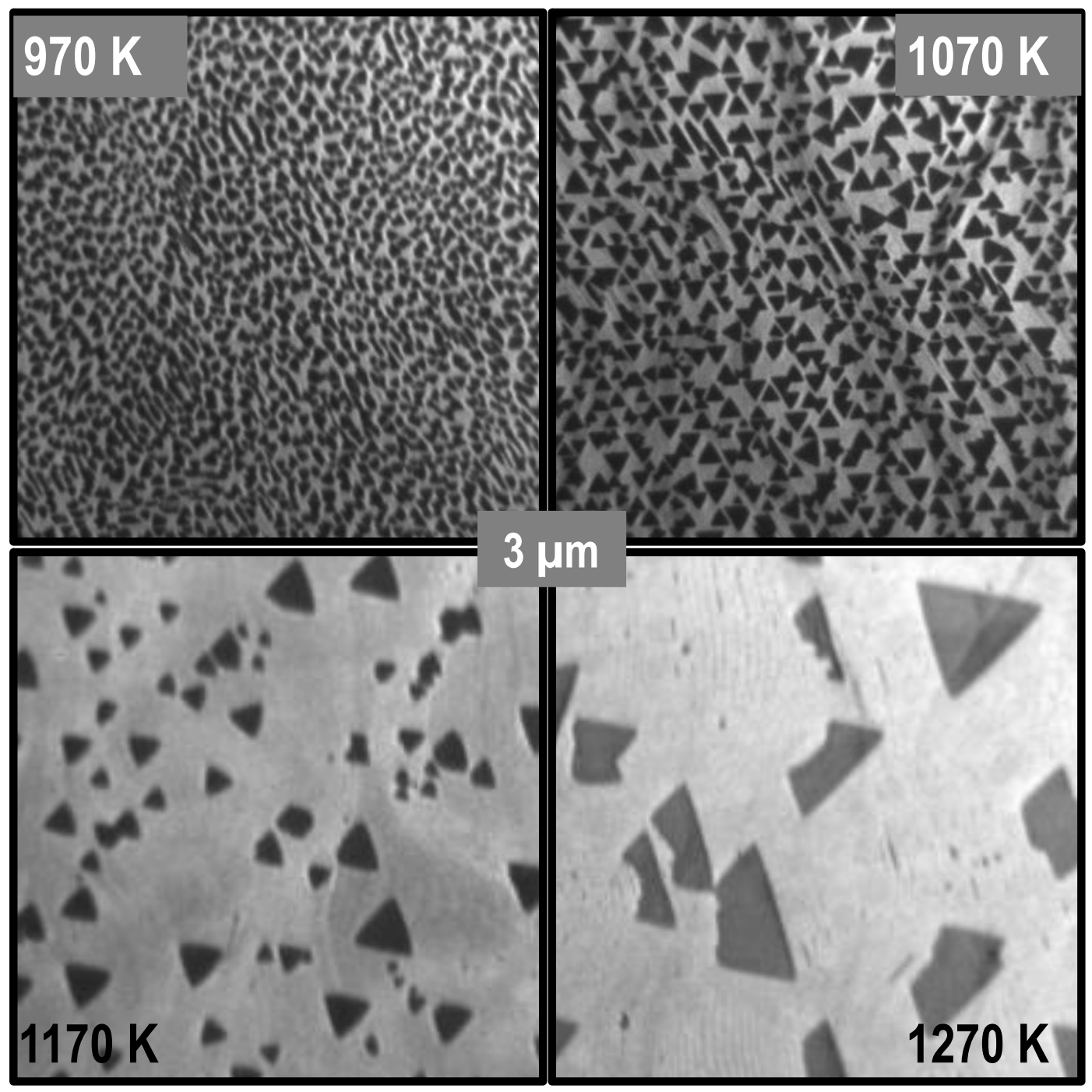

Figure 6. LEEM images of growth at $970,1070,1170$ and $1270 \mathrm{~K}$ of $\mathrm{CeO}_{\mathrm{x}}$ on to a $\mathrm{Ru}(0001)$ substrate. The ceria islands appear as dark shapes on the bright $\mathrm{Ru}$ substrate.

The atomic structure of $\mathrm{CeOx}$ islands grown at higher temperatures was also investigated using STM by Hasegawa et al. [52], where the terrace width and island size were observed to change drastically with growth temperatures of $1040 \mathrm{~K}$ and $1060 \mathrm{~K}$ (Figure 7), in agreement with our previous findings from LEEM (Figure 1). STM images of islands of differing thickness ( $\sim 6 \mathrm{ML}$ and $\sim 8 \mathrm{ML}$ ) with atomically flat and well-defined step edges are shown in Figure 7(a-b). The inset of Figure 7(a-b) shows a typical terrace with atomic resolution. Figure 7(c) displays a moiré pattern observed on the second layer of the film indicating a lattice mismatch between the $\mathrm{Ru}$ substrate and the ceria layer. Figure $7(\mathrm{~d})$ is the corresponding LEED pattern for a ceria over layer prepared at $1060 \mathrm{~K}$ and an average island thickness of $2 \mathrm{ML}$. The ordered structure can be best described with the unit of the triangle superimposed in the STM image of Fig. 7(c). The unit has the periodicity of five times of the nearest neighbor $(\mathrm{NN})$ distance of the oxygen atoms of the $\mathrm{CeO}_{2}(111)$ film. This result 
correlates well with the structure of $\mathrm{CeO}_{2}(111) / \mathrm{Ru}(0001)$ as determined from high-resolution LEED [26], which will be presented in the next section.
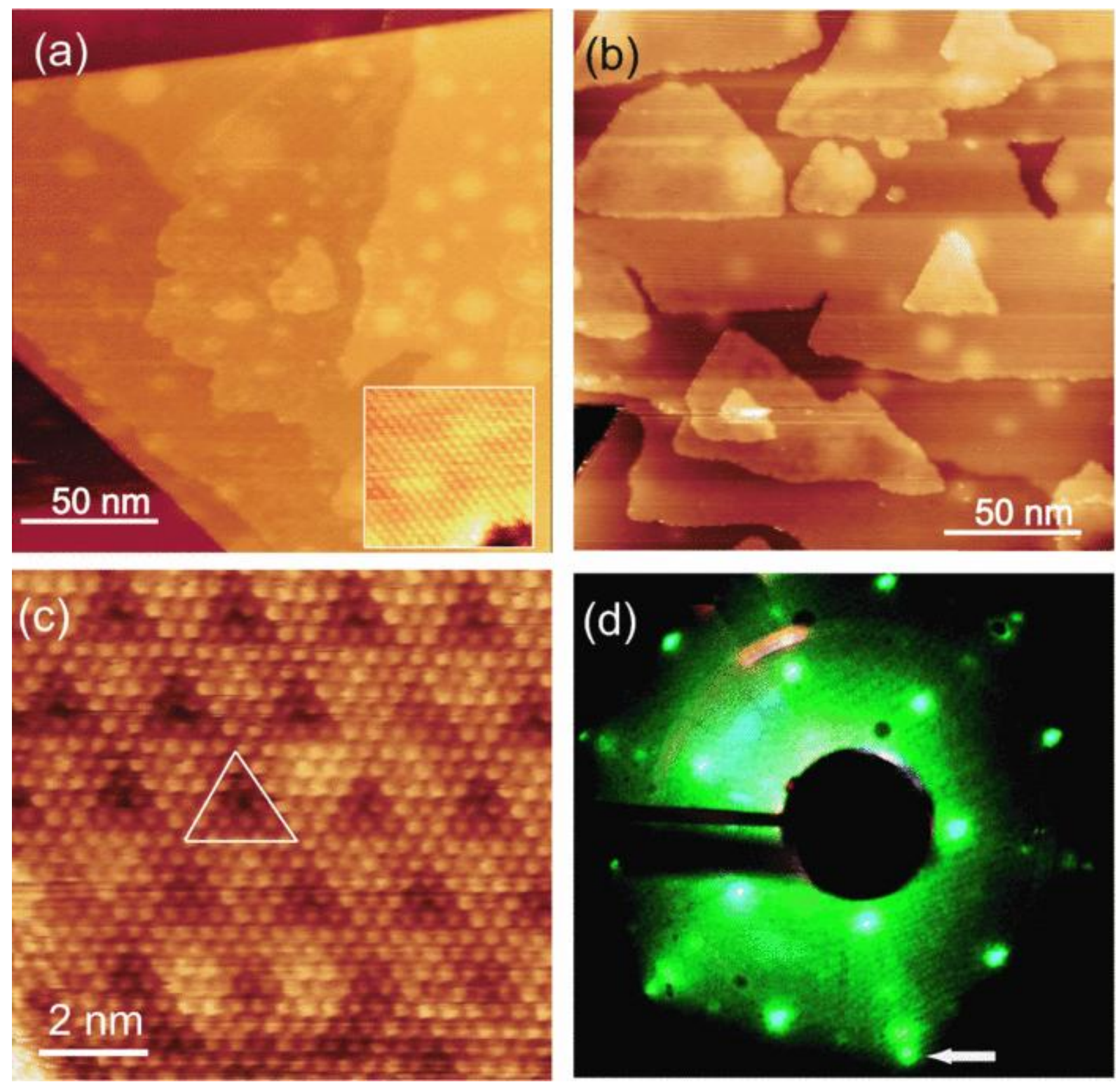

Figure 7. (a-b) Ceria film grown at $1040 \mathrm{~K}$ (a) and $1060 \mathrm{~K}$ (b) in an oxygen background of $5 \times 10^{-7}$ Torr. The thicknesses of the majority of the islands are (a) $6 \mathrm{ML}$ and (b) $8 \mathrm{ML}$. (c) Magnified image of the terrace, which is 2 ML high from the metal surface. A moiré pattern with $5 \times 5$ periodicity with respect to the $\mathrm{CeO}_{2}(111)$ surface is marked by a white triangle. (d) LEED pattern observed for the surface of (c). A spot corresponding to the moiré superstructure is marked by an arrow. Reprinted with permission from [52]. Copyright 2014, AIP Publishing LLC.

\section{High-resolution LEED and Interface Analysis}


In all of our LEED investigations of $\mathrm{CeO}_{2}(111) / \mathrm{Ru}(0001)$, we observe $\mathrm{p}(1.4 \times 1.4)$ spots, attributed to ceria. To get an even more detailed insight into reciprocal space structure and to reveal the structural origin of the $\mathrm{p}(1.4 \times 1.4)$ phase, that is, whether it is commensurate or incommensurate, we obtained LEED with very low inelastic background [26] for a sample grown at $700{ }^{\circ} \mathrm{C}$ as displayed in Figure 8a. A magnified view of the region enclosed by white lines in Figure $8 \mathrm{a}$ is displayed in Figure $8 \mathrm{~b}$. As expected, the LEED pattern exhibits the sixfold symmetric $\mathrm{Ru}(0001)-(1 \times 1)$ diffraction spots (black circles) as well as the well-known $\mathrm{p}(1.4 \times 1.4)$ ceria spots (red circles). A $\mathrm{p}(2 \times 1)$-O phase with an additional splitting due to antiphase domain boundaries is also visible (blue ellipse). Diffraction spots belonging to rotated ceria domains occur at positions highlighted by red circular lines. The most important observation from Figure 8 however is the presence of the small (n/7) spots, whose positions are marked by small black dots. These diffraction peaks are observed for the first time, probably due to the superior resolution and sensitivity of the energy-filtered LEEM instrument as compared to a conventional LEED system. Since the (n/7) spots all exhibit comparable intensities, we do not observe the characteristic, damped envelope function typical of a moiré pattern, which would indicate a coincidence lattice for ceria on $\mathrm{Ru}(0001)$. This observation clearly reveals that ceria on $\mathrm{Ru}(0001)$ develops a $(7 \times 7)$ superstructure and is therefore commensurate. The (5/7) spots exhibit the highest intensity because they coincide with the $(1 \times 1)$ diffraction spots of bulk $\mathrm{CeO}_{2-}(111)$. The LEED pattern can, therefore, be explained by a superposition of the diffraction from $\mathrm{CeO}_{2-\delta}(111)$-type islands and from regions where the islands are sufficiently thin that we can still probe the $(7 \times 7)$ superstructure at the interface between the ceria and substrate. The presence of commensurateness implies that the atomic interface between the ceria islands and the ruthenium substrate is well-ordered and coherent.

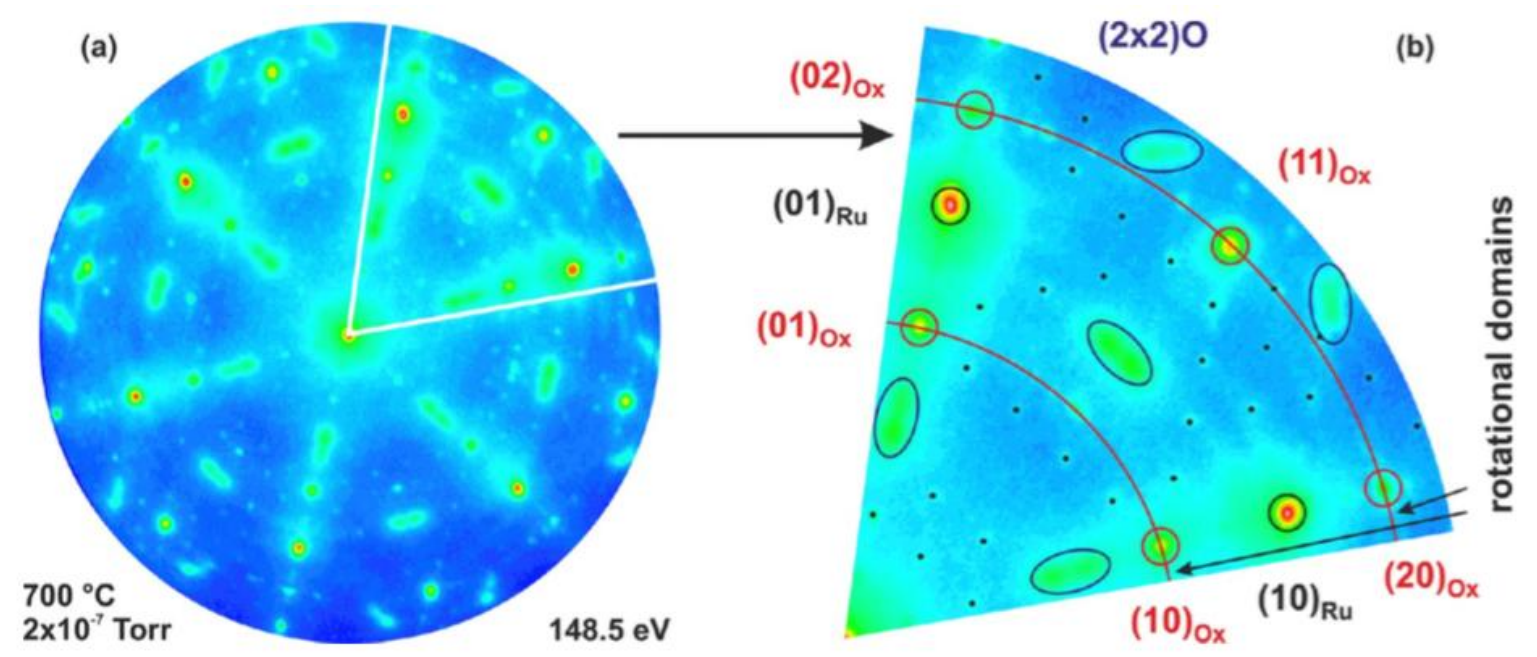


Figure 8. LEED image of highly oxidized ceria grown at a $700{ }^{\circ} \mathrm{C}$ substrate temperature and an oxygen partial pressure of $2 \times 10-7$ Torr. Panel (b) shows a magnified part of the LEED pattern. The LEED pattern exhibits intense $\mathrm{Ru}(0001)$ substrate spots and the $\mathrm{p}(1.4 \times 1.4)$ ceria phase with an additional $(7 \times 7)$ superstructure which is highlighted by small black dots. A $\mathrm{p}(2 \times 1) \mathrm{O}$ phase is observed with an additional splitting of the diffraction spots due to the presence of antiphase domain boundaries. The thin red circular lines highlight possible positions for ceria rotational domains that may be found at this growth temperature. Reprinted with permission from [26]. Copyright 2013 American Chemical Society.

\section{Carpet Growth Mechanism}

The presented LEEM studies support a mechanism of growth that is a carpet-like model for the ceria islands as proposed by Flege et al. [25]. This is depicted schematically in Figure 9. This carpet-like growth is a result of the balance between the strain energy of the elastically distorted oxide film in more densely-stepped areas of the substrate and the oxide-substrate interaction energy in the flat regions. When the "easy" growth direction coincides with the local substrate step orientation as defined by its outward normal, the continuation of the oxide structure over the step results in a larger separation of the oxide film from the lower substrate terrace in the vicinity of the step (Figure 9d). This scenario implies that the stiffness of the oxide film prevents it directly following the curvature of the substrate topography, which reduces the interaction with the underlying substrate. The additional elastic deformation energy and the reduced interaction energy with the substrate together contribute to a net increase in the total energy per unit oxide film area. Even in the absence of any additional kinetic effects, this increase in total energy results in a substantial effective activation energy for growth over a step edge. Consequently, when the step height is too large, as encountered for step bunches on the Ru surface, the elastically deformed area and associated strain energy is large, inhibiting overgrowth as shown in Fig. 9(e). Similarly, when a straight ceria island edge encounters a step with parallel-oriented outward normals (see Fig. 9(c)), then the area that needs to be deformed is also large, again hindering further growth in this direction. This carpet-like growth mode has previously been proposed for thin $\mathrm{NaCl}$ films on $\mathrm{Ge}(100)$ [53] based on spot-profile analysis LEED investigations [54]. This observation suggests that this growth mode may be considered a rather general feature of strongly ionic binary films, which have only a moderate interaction with the substrate. Supporting this is the observation that seemingly unrestricted carpet-like growth is found for graphene on single [55] [48] and polycrystalline [56, 57] ruthenium surfaces. The well- 
established strong interaction between graphene and ruthenium emphasizes that the energy balance between strain energy and film-substrate interaction energy is critical to the behavior during growth. Further support for the carpet-growth model is provided by the behavior around substrate step bunches and grain boundaries, which are significant obstacles for lateral overgrowth by the oxide. Interestingly, this results in the evolution of irregular island shapes, even approaching quasi-linear, stripe-like structures for oxide islands that have nucleated near substrate step bunches.

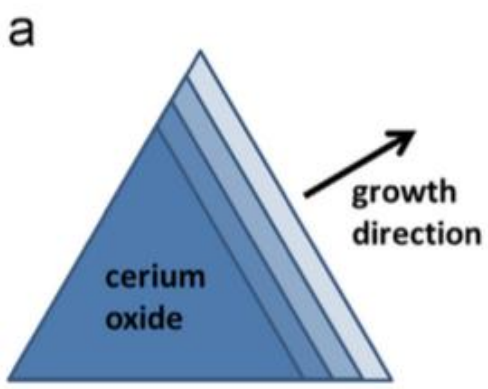

flat Ru terrace

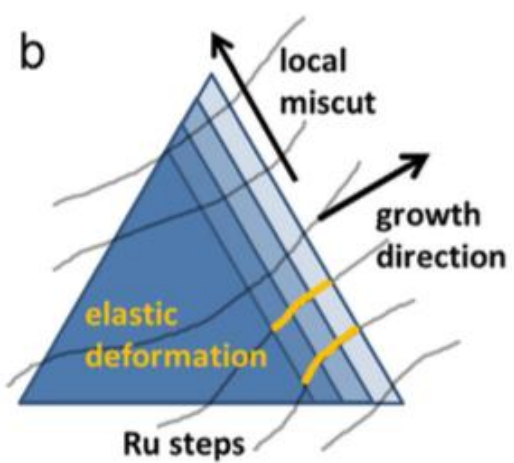

Ru steps

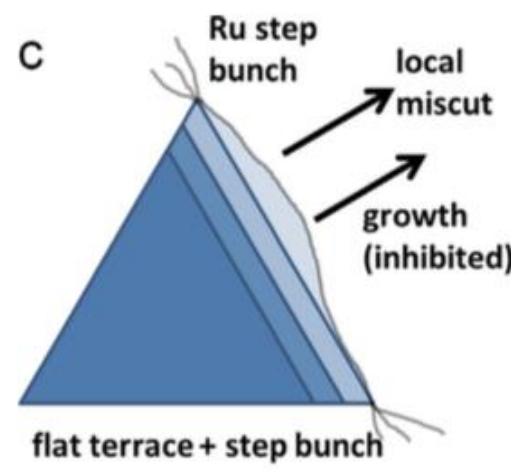

growth

inhibited
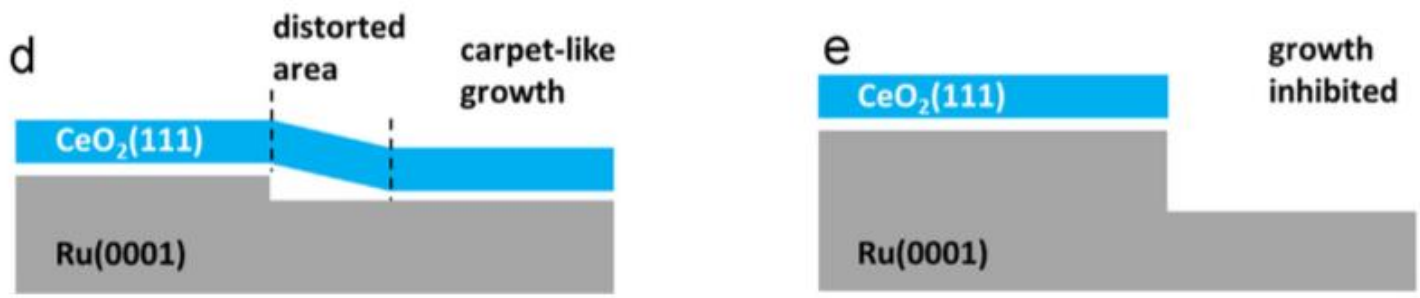

Figure 9. Schematic of the carpet growth model for $\mathrm{CeO}_{2}(111)$ on $\mathrm{Ru}(0001)$. (a) Unperturbed growth of ceria adopting the shape of equilateral triangles on (a) an infinitely flat terrace and (b) on a stepped surface with the local miscut oriented perpendicular to the main island growth direction. (c) Inhibited ceria island growth due to parallel alignment of growth direction and local substrate miscut orientation. (d) Carpet-like growth over low substrate steps. (e) Inhibited growth over high substrate steps. Reprinted from [25], with permission from Elsevier.

In the previous sections we have established a comprehensive picture of the ceria growth characteristics on the $\mathrm{Ru}(0001)$ surface by reactive MBE techniques. This intimate knowledge not only allows tailoring the nanoscale morphology and atomic structure to the targeted application, but also a clear strategy to identifying key structural features and link them with the chemical reactivity, thereby providing a well-defined route to unraveling the structurefunction relation in ceria-based catalytic chemistry. 


\section{Chemical State and Reactivity}

The most common method for determining the oxidation state of the cerium cation within ceria is via X-ray photoemission spectroscopy of the Ce 3d, 4d, or $4 \mathrm{f}$ levels. An example from Flege et al. [25] of such an identification of the chemical state of the ceria islands using energy-filtered XPEEM at the Ce $4 \mathrm{~d}$ core level is shown in Figure 10a, comparing a fully oxidized $\mathrm{CeO}_{2}$ film (red line) and a partially reduced $\mathrm{CeO}_{\mathrm{x}}$ film (blue line). It is possible to derive the oxidation state of ceria by comparing the peak intensities of the peaks $\mathrm{W}^{\prime \prime \prime}$ and $\mathrm{X}^{\prime \prime \prime}$ with the intensity of the remaining spectrum [58]. Figure 10a shows the background-corrected Ce $4 \mathrm{~d}$ spectrum of a sample grown at $1100 \mathrm{~K}$ in $5 \times 10^{-7}$ Torr $\mathrm{O}_{2}$ (red line). Due to the typical lower resolution of the photoelectron spectra acquired in XPEEM mode as compared to available high-resolution X-ray photoelectron spectra [59], the peaks are slightly broader than usual. From the relative intensity distribution of the peaks $\mathrm{W}^{\prime \prime \prime}$ and $\mathrm{X}^{\prime \prime \prime}$ compared to peaks $\mathrm{A}$, $\mathrm{B}$, and $\mathrm{C}$, we can conclude that the ceria is nearly fully oxidized under these growth conditions. The blue line in Figure 10a shows the $\mathrm{Ce} 4 \mathrm{~d}$ spectrum after background subtraction, of a sample grown at $630 \mathrm{~K}$ in $1 \times 10^{-8}$ Torr $\mathrm{O}_{2}$. Here, we find that the peaks $\mathrm{W}^{\prime \prime \prime}$ and $\mathrm{X}^{\prime \prime \prime}$ contribute far less intensity to the spectrum, illustrating a lower oxidation state of ceria that is consistent with the less oxidative conditions during the film growth. Figure $10 \mathrm{~b}$ shows the $I(V)$-LEEM spectra for the two films probed with $\mathrm{X}$ rays in Figure 10a, and illustrates how the fine structure in the $I(V)$ curve also allows us to identify the oxidation state of the ceria. The red and blue lines, corresponding to the fully and partially oxidized films, respectively, clearly display significant differences.

In general, the analysis of $I(V)$-LEEM data follows two different procedures. In the first, the $I(V)$ curves are used to provide a fingerprint to identify the local atomic structure by comparing with experimentally obtained $I(V)$ curves from reference structures. Yet, a more complex interpretation may be achieved by comparing the experimental $I(V)$ curves to theoretical reflectivity spectra that have been calculated within an ab initio scattering theory that takes into account the unoccupied complex band-structure of the model catalyst [60]. However, for correlated electron systems such as ceria this analysis is very complex, currently prohibiting the analysis of trial structures with a large number of basis atoms per unit cell [43]. Yet, even qualitatively it is clear that the $I(V)$ curve changes upon change in average oxidation state, which directly implies that $I(V)$ spectra can be used as local probes within an 
oxidation state analysis with the nanometer spatial resolution provided by the LEEM technique.

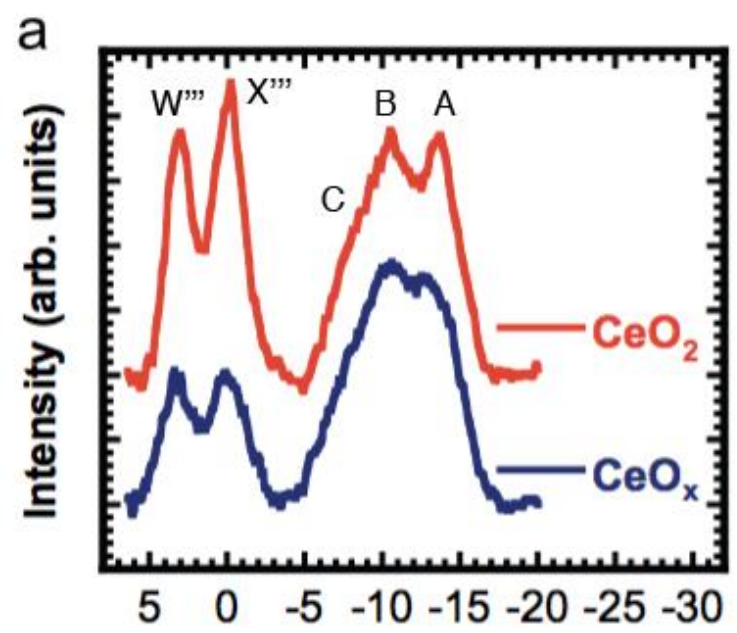

Relative Binding Energy (eV)

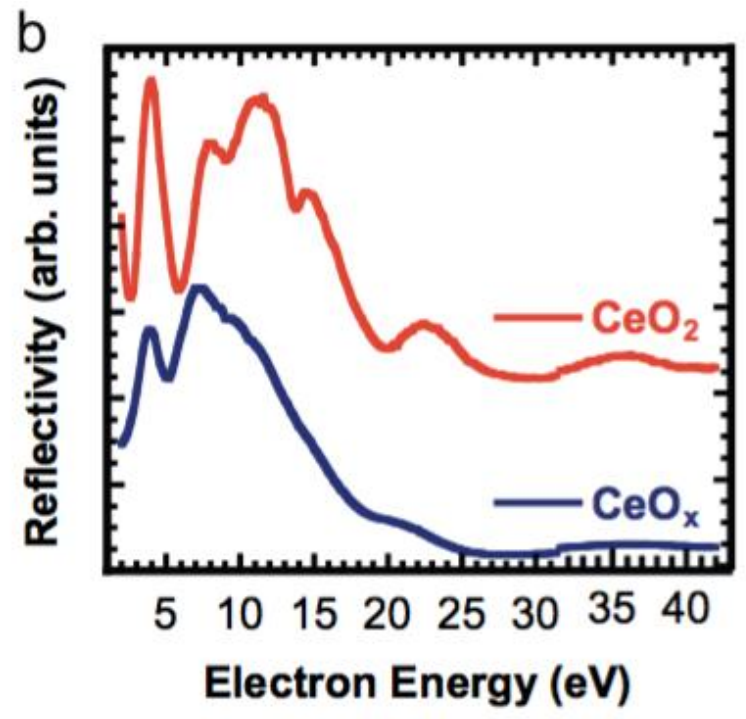

Figure 10. (a) Ce $4 d$ soft $x$-ray photoemission (hv = $165 \mathrm{eV}$ ) and (b) corresponding $I(V)$ LEEM spectra collected for nearly fully oxidized ceria $\left(\mathrm{CeO}_{2}\right)$ and moderately reduced ceria $\left(\mathrm{CeO}_{\mathrm{x}}\right)$ prepared on $\mathrm{Ru}(0001)$. Reprinted from [25], with permission from Elsevier.

An alternative method for determination of the ceria oxidation state with X-ray photoemission techniques is via X-ray absorption spectroscopy, often of the Ce M4,5 edge whose appearance is particularly sensitive to changes in the electronic configuration of the cation. One advantage of this method, especially when employed in combination with XPEEM, is the improved signal-to-noise ratio, which directly results in improved lateral resolution and shorter image acquisition times, although this comes at the sacrifice of some of the surface sensitivity as compared to the XPS method displayed in Figure 10. Figure 11 shows the evolution of the XAS spectra obtained by Höcker et al. [61] from a single ceria nanoparticle with increasing exposure to $\mathrm{H}_{2}$. $\mu$-XAS of the as-prepared island (bottom spectrum in Figure 11a) indicates that the microparticle is nearly fully oxidized $\left(\mathrm{CeO}_{2}\right)$, which is homogeneous across the island [61]. After dosing $25 \mathrm{~kL}$ of hydrogen at a sample temperature of $430^{\circ} \mathrm{C}$, however, additional peaks are observed on the lower energy side of both the M4 and M5 edges, consistent with $\mathrm{Ce}^{3+}$ formation $[62,63]$. The spectrum is still dominated by the $\mathrm{Ce}^{4+}$ peaks, showing that the complete particle is only mildly reduced, indicating that the reduction by $\mathrm{H}_{2}$ is a slow, activated process. This observation suggests the presence of a considerable kinetic barrier for $\mathrm{H}_{2}$ dissociation over $\mathrm{CeO}_{2}(111)$, a finding which disagrees with earlier calculations that predicted a barrier of only $0.2 \mathrm{eV}$ [64]. However, better agreement is found 
with recent DFT studies that predict a kinetic barrier of about $1 \mathrm{eV}$, attributed to a slow dissociation step of the chemisorbed $\mathrm{H}_{2}$ molecule into separate hydroxyl groups $[65,66]$. To derive the oxidation state of the ceria from the Ce M5-edge XAS data, we applied a linear combination of the $\mathrm{Ce}^{4+}$ and $\mathrm{Ce}^{3+}$ peaks [62] as shown in Figure 11b,c. This yielded a stoichiometry of $\mathrm{CeO}_{1.85}$ after dosing $25 \mathrm{~kL}$ hydrogen (Figure 11b) and $\mathrm{CeO}_{1.68}$ after dosing of an additional $43 \mathrm{~kL}$ of $\mathrm{H}_{2}$ (Figure 11c).



Figure 11. (a) Ce M4,5 X-ray absorption spectra acquired from an individual ceria microparticle in XPEEM during the reaction with $\mathrm{H}_{2}$. Bottom: the initial $\mathrm{CeO}_{2}$. Center: after dosing $25 \mathrm{~kL} \mathrm{H}_{2}$ at $700 \mathrm{~K}$. Top: after $68 \mathrm{~kL} \mathrm{H}_{2}$ at $700 \mathrm{~K}$. (b,c) Fitting of the Ce M5 edge by a linear combination of $\mathrm{Ce}^{3+}$ (dark green) and $\mathrm{Ce}^{4+}$ (light green) related peaks. Reprinted from [61], with permission.

In order to probe any changes in the surface structure of the ceria that accompany the reduction process in $\mathrm{H}_{2}, \mu$-LEED was conducted [61] on single particles with an incident electron beam size of $500 \mathrm{~nm}$. This procedure is depicted in Figure 12; the changes in the LEED pattern from an individual particle (as marked in the inset of Figure 12a) recorded in real-time are presented as a time-lapse sequence in Figure 12a-d. Before hydrogen is introduced, only the $(1 \times 1)$ integer spots of $\mathrm{CeO}_{2}(111)$ (Figure 12a) are observable. After dosing $500 \mathrm{~L}_{\text {of }} \mathrm{H}_{2}$ at $5 \times 10^{-7}$ mbar, additional spots emerge (Figure 12b), which are a direct 
consequence of the local ordering of the oxygen vacancies resulting from dissociative adsorption of $\mathrm{H}_{2}$ and subsequent surface reduction. These superstructure spots remain constantly visible throughout the reduction process, indicating that the surface remains crystallographically ordered at all times. The superstructure spots (Figure 12b) have a periodicity of 2.6 with respect to the integer spots of $\mathrm{CeO}_{2}$. This period is dependent on both the $\mathrm{H}_{2}$ pressure and dose. Increasing the pressure to $1 \times 10^{-6}$ mbar induces larger periodicities, resulting in a commensurate $(3 \times 3)$ superstructure (Figure 12c), which remains unchanged upon subsequent dosing at this pressure. However, at a $\mathrm{H}_{2}$ pressure of 2 $\times 10^{-6}$ mbar the superstructure spots move apart and finally appear at the (1/4) and (3/4) positions as shown in Figure 12d. This coincides with the emergence of a stationary spot at the $(1 / 2)$ position, which together with the satellite spots results in a $(4 \times 4)$ periodicity. Quantitatively, this is concomitant with a slight in-plane lattice expansion of about (1 \pm $0.3) \%$ with respect to the as-prepared $\mathrm{CeO}_{2}(111)$. The $(4 \times 4)$ pattern is attributed to the formation of the bixbyite $\mathrm{Ce}_{2} \mathrm{O}_{3}(111)$ phase, composed entirely of $\mathrm{Ce}^{3+}$ [67], whereas the $(3 \times$ 3) periodicity has previously been attributed to a stable ceria phase with stoichiometry $\mathrm{CeO}_{1.67}$ [68]. Interestingly, a much higher $\mathrm{H}_{2}$ dose is required for significant reduction as measured by $\mu$-XAS than to reach full reduction in the $\mu$-LEED experiments. This observation is explained by considering the completely different probing depths of the two methods. While LEED at $40 \mathrm{eV}$ kinetic energy probes just a few tenths of a nanometer into the sample, the escape depth of the very slow electrons $(2.6 \mathrm{eV})$ in XAS is orders of magnitude larger, thus revealing an oxygen concentration gradient within the ceria islands. 


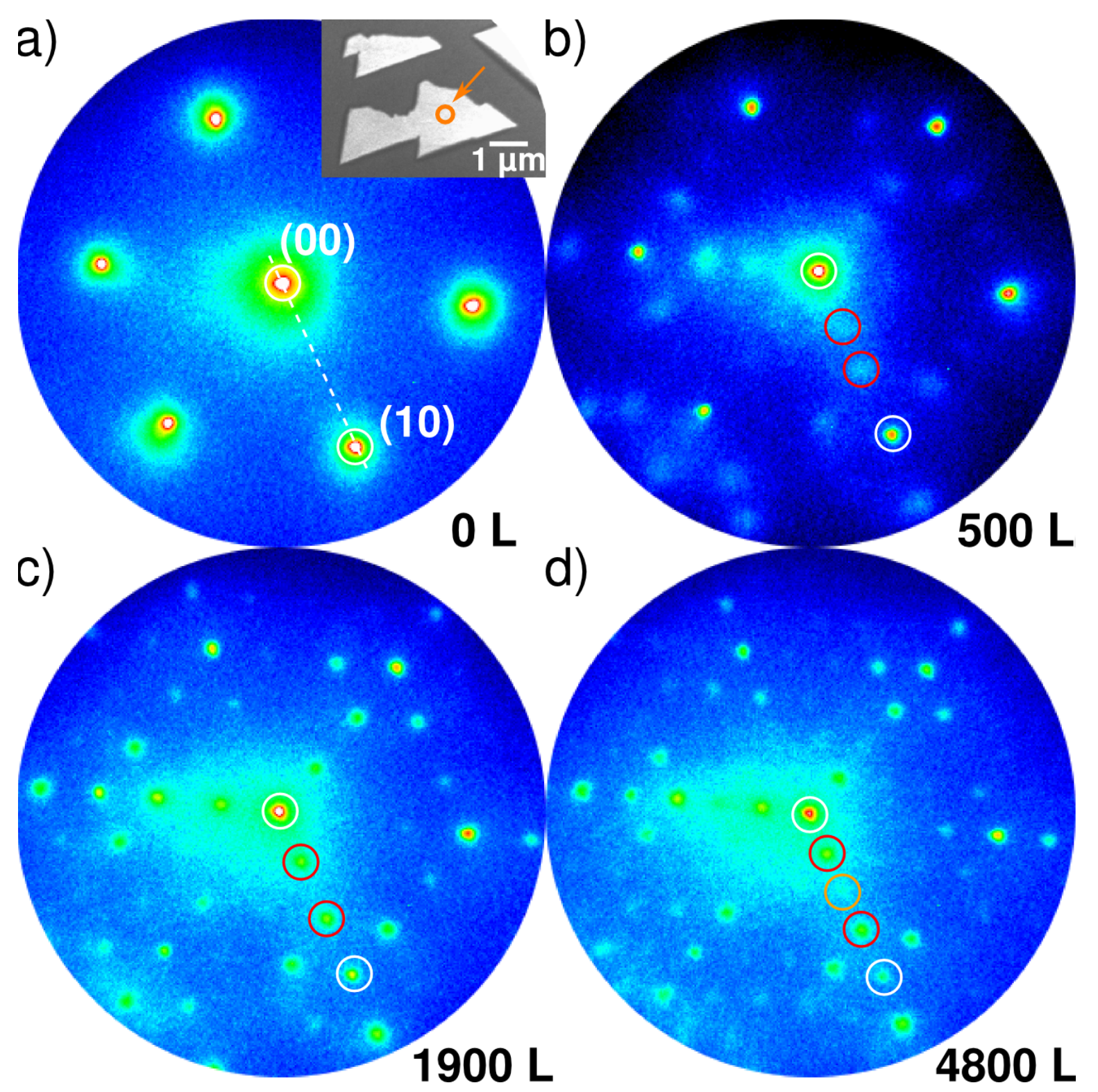

Figure 12. (a-d) $\mu$-LEED images obtained during the chemical reduction of a single ceria particle by hydrogen (exposures quoted in L) at $700 \mathrm{~K}$. White circles indicate the reflections of $\mathrm{CeO}_{2}$. The positions of the superstructure spots are indicated by red (moving spots) and orange circles (stationary half-order spot). (a) Inset: LEEM image of the surface ( $\mathrm{E}=15.3$ $\mathrm{eV})$. The orange circle indicates the electron beam spot size and position during the reduction experiment. Reprinted from [61], with permission.

In order to explore the effects of chemical reduction of $\mathrm{CeO}_{2}(111) / \mathrm{Ru}(0001)$, we have exposed a film to methanol at $300 \mathrm{~K}$, followed by gentle annealing [60]. A LEEM image of the as-prepared $\mathrm{CeO}_{2}(111)$ islands on $\mathrm{Ru}(0001)$ is displayed in Figure 13a. In the image, all of the ceria islands appear homogeneously bright, suggesting a uniform oxidation state after growth. After methanol exposure and annealing, however, significant intensity variations are 
observed across the surface of the ceria islands (Figure 13b). This image contrast, whose chemical interpretation is corroborated by the presence of distinct local $I(V)$ curves [60], clearly indicates a local variation in oxidation state although interestingly the brighter and darker patches show no apparent relation to the island shape or size.

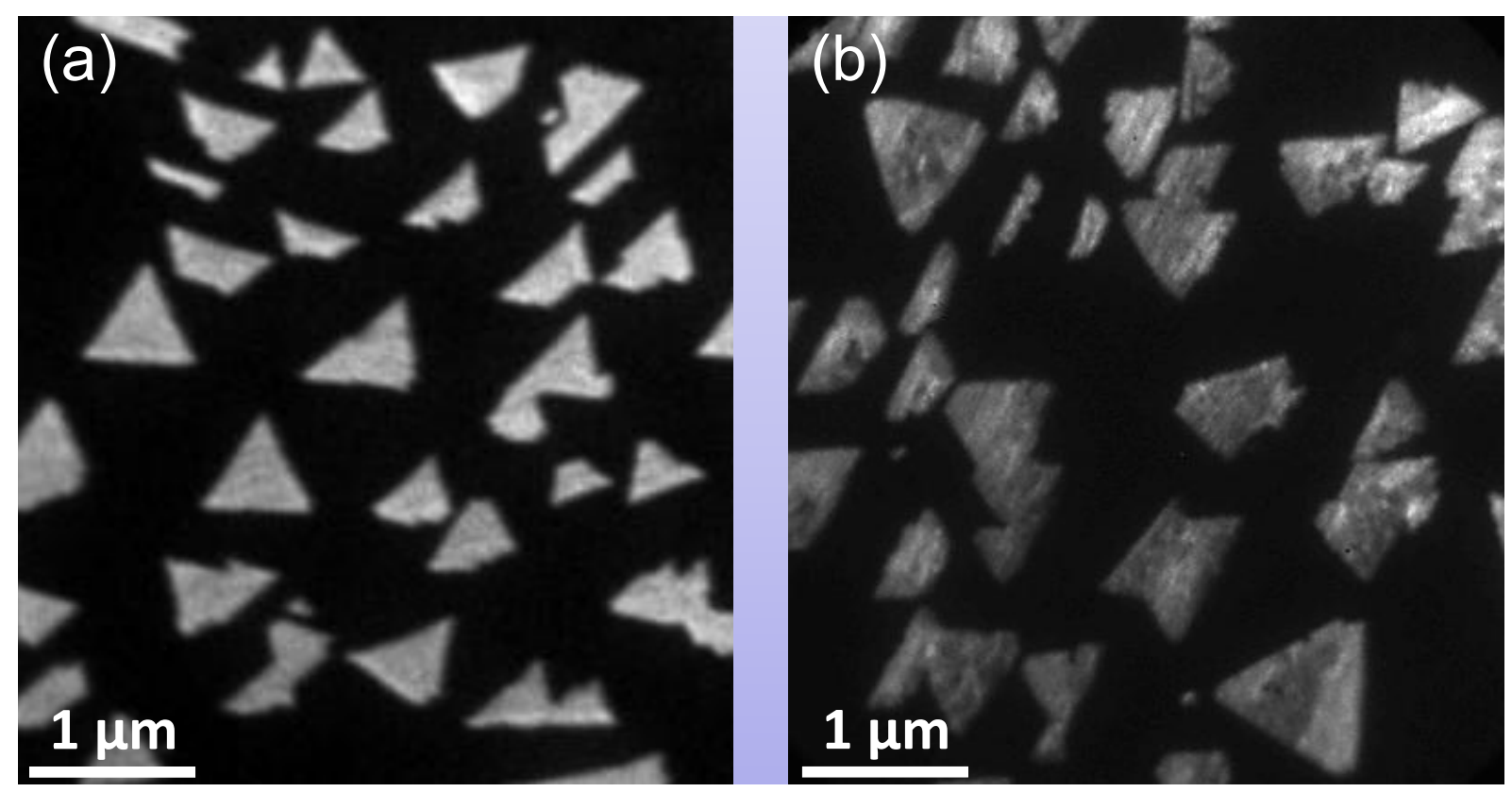

Figure 13. LEEM images $(E=15.4 \mathrm{eV})$ recorded (a) after growth and (b) after reduction by exposure to methanol subsequent annealing. The contrast on the ceria islands is due to local varying stoichiometry. Adapted with permission from [60]. Copyrighted by the American Physical Society.

To provide a comparison to the reduction by methanol displayed in Figure 13, which shows clear heterogeneity across the ceria islands as the reaction progresses, the reduction of the ceria by $\mathrm{H}_{2}$, previously examined spectroscopically in Figure 11 and 12, was probed with high resolution LEEM imaging, the results of which are displayed in Figure 14 [61]. After partial reduction by $\mathrm{H}_{2}$, the ceria microparticles (dark at these imaging conditions) do not exhibit a homogeneous intensity (also see inset of Figure 12a, which has been taken at virtually identical imaging conditions as Figure 13) but display two distinct levels of intensity (Figure 14a). With further hydrogen exposure, this bimodal contrast completely disappears. The local $I(V)$ reflectivity curves, which are directly linked to the local surface structure [43] and stoichiometry [60], are used to identify and separate the two domains on the nanometer scale. (Figure 14b) Comparison to reference spectra for $\mathrm{Ce}_{2} \mathrm{O}_{3}$ (bixbyite), $\mathrm{CeO}_{x}(3 \times 3)$, and $\mathrm{CeO}_{2}$ (fluorite) reveals that the areas appearing dark in Figure 14a at $16.2 \mathrm{eV}$ can be assigned to 
$\mathrm{Ce}_{2} \mathrm{O}_{3}(111)$ whereas the brighter particle areas indicate the $\mathrm{CeO}_{x}(3 \times 3)$ phase (Figure 14b). After exposure for several hours to $2 \times 10^{-6} \mathrm{mbar}_{2}$, the variable contrast within the ceria particles vanishes and the $I(V)$ curve shows the expected fully reduced $\mathrm{Ce}_{2} \mathrm{O}_{3}(111)$ fingerprint.

a)

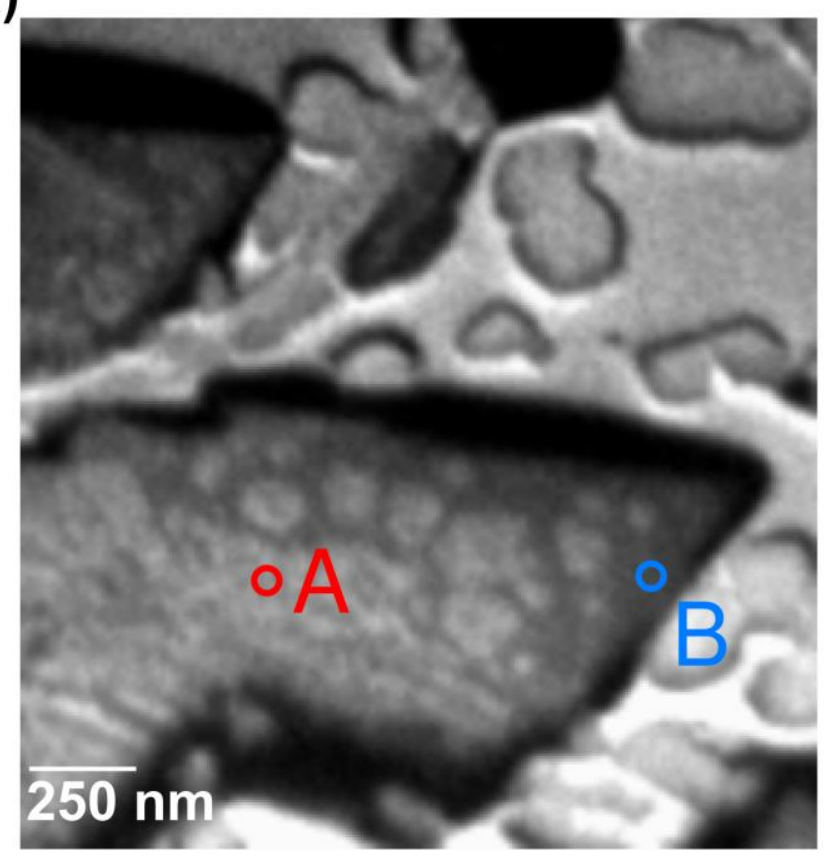

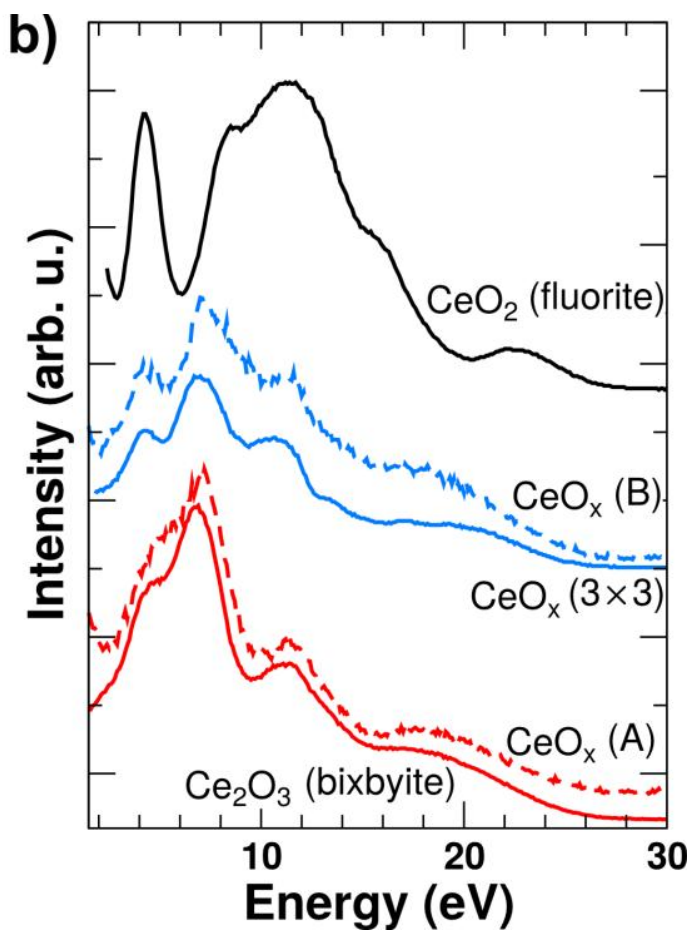

Figure 14. (a) LEEM image $(E=6.2 \mathrm{eV})$ of a ceria film after reduction by hydrogen showing inhomogeneous reduction of the cerium oxide particles. (b) $I(V)$ fingerprints recorded from highlighted areas "A" and "B" (dashed lines) and compared to $I(V)$ reference spectra (solid lines). The bright patches in panel (a) appear upon prolonged $\mathrm{H}_{2}$ exposure and, based on $I(V)$ and $\mu$-LEED analysis, are consistent with local hydrogen incorporation. Reprinted from [61], with permission. 


\section{Future Prospects of Probing In Situ Reactivity}

The ability to dynamically observe reactions as they occur over the surfaces of catalysts is essential to the clear and unambiguous establishment of active ingredients and insights into the mechanism of reactions. Static microscopy or spatially averaged spectroscopy or scattering is certainly important yet is limited to inference or extrapolation of the active state of the catalyst, often before or after reaction has taken place. The degree of surface heterogeneity that results and often accompanies such processes is a major obstacle to many methods. Direct causality where a reactant is activated and converted to a product over a specific surface site or region is thus challenging and is ultimately the 'holy grail' in being able to implicate the true nature of catalysts and reactions.

Efforts to study in situ surface reactivity are therefore clearly motivated by a need to take images, spectroscopy and scattering in a rapid, time-dependent, and spatially resolved manner under the appropriate reaction conditions. Combing all three of these parameters into one in situ method applied in real time may only be possible with a combination of LEED/LEEM/XPEEM, where correlative local area diffraction, fast images and X-ray spectroscopy can be brought to bear towards the probe of a simple reaction. This has been demonstrated for the first time in the case of $\mathrm{CeO}_{x}-\mathrm{Ru}$ (Figure 15) under reaction with $\mathrm{H}_{2}$ in real-time. The $\mathrm{H}-\mathrm{H}$ activation is especially important for reactions including $\mathrm{CO}_{2}$ and olefin hydrogenation for conversion to alcohols and oligomers, respectively. It was possible to identify reduced phases as they evolve on the surface of the $\mathrm{CeO}_{\mathrm{x}}$ and which were identified with local area electron diffraction and X-ray spectroscopy. Together with time-resolved I(V)-LEEM, this experimental methodology is also able to unravel cooperative effects as, e.g., in reactant spillover over oxygen-rich $\mathrm{Ru}(0001)$ surfaces [69, 70], whose oxidation we have also followed from submonolayer oxygen coverages to formation of the bulk-like oxide phases $[71,72]$. Hence, the full tool set for spatially resolved monitoring of different cerium oxidation states as well as of the ruthenium support at various levels of oxidation during redox reactions over ceria/Ru surfaces is readily available, offering the exciting possibility to address complex reactions involving dynamic transformations of all surface components in the catalytic reaction.

The ability to perform this methodology beyond just single reactants and in fact with near operando catalytic reactions is not yet realized, but is the future prospect for advanced 
characterization of surface reactions in real time. The $\mathrm{CeO}_{\mathrm{x}}-\mathrm{Ru}(0001)$ system, now with a large body of work aimed at its fundamental characterization of its growth and local chemical state, will be an important benchmark for such studies. A near atomic level model of structural changes that occur during a reaction may be obtainable while under steady state and pulsed reactant conditions. In addition, spectroscopy coupled to atomic structure may also be very helpful in identifying reaction mechanisms where $\mathrm{C}$, $\mathrm{O}$ containing adsorbates that accumulate on surface sites could be identified (XPEEM) with high resolution spectroscopy. Intentional perturbation of the surface atomic geometry either as grown or with pre-treatments can also be tested systematically to further establish design principles under which reactantsubstrate transformations may occur leading to optimum or destructive transformations (deactivation).



Figure 15. In situ LEEM/PEEM image of $\mathrm{CeOx}-\mathrm{Ru}(0001)$ island under $\mathrm{H}_{2}$ activation, showing regions of surface structure evolve as a function of $\mathrm{H}_{2}$ activation in real time.

\section{Conclusions}


The $\mathrm{CeO}_{\mathrm{x}}-\mathrm{Ru}(0001)$ surface can be prepared by reactive molecular beam epitaxy to yield well-defined (111)-oriented nano-islands, micron-sized particles, and continuous films that allow for the investigation of the unique properties of cerium oxide. The atomic structure and chemical state have been well characterized with STM and LEEM/LEED with a clear perspective of the atomic arrangement of the last layer of $\mathrm{O}-\mathrm{Ce}-\mathrm{O}$ atoms and the defect states that prevail. Chemical states of the surface $\left(\mathrm{Ce}^{4+} \mathrm{vs} \mathrm{Ce}^{3+}\right)$ has been identified using X-ray methods such as XPS, XAS and X-PEEM and compared to $I(V)$-LEEM reflectivity data. The growth mode of ceria overlayers on $\mathrm{Ru}(0001)$ was established through dynamic LEEM studies and identified as a carpet-mode of growth, transforming into different surface architectures dependent on the oxygen potential and thermodynamics. The reactivity of the $\mathrm{CeO}_{\mathrm{x}}-\mathrm{Ru}(0001)$ surface was studied upon reaction with methanol and $\mathrm{H}_{2}$, with interesting structural transformations that predominantly favored reduced surface state during the activation of reactants. The $\mathrm{CeO}_{\mathrm{x}}-\mathrm{Ru}(0001)$ system stands out as an important prototype model system for the understanding of ceria catalytic chemistry.

\section{Acknowledgements}

This work was supported by the U.S. Department of Energy, Office of Science, Office of Basic Energy Sciences, and Catalysis Science Program under contract No. DE-SC0012704. Furthermore, we wish to thank our coauthors R. D. Eithiraj, J. Falta, J. Höcker, J. Hrbek, B.

Kaemena, E. E. Krasovskii, A. Locatelli, T. O. Menteş, A. Meyer, J. A. Rodriguez, J. T. Sadowski, A. Sala, and Th. Schmidt for their valuable contributions to this work. Support from the European COST Action CM1104 is gratefully acknowledged.

\section{References}

[1] Q. Fu, H. Saltsburg, M. Flytzani-Stephanopoulos, Active Nonmetallic Au and Pt Species on Ceria-based Water-Gas Shift Catalysts, Science, 301 (2003) 935-938.

[2] J.A. Rodriguez, S. Ma, P. Liu, J. Hrbek, J. Evans, M. Pérez, Activity of $\mathrm{CeO}_{\mathrm{x}}$ and $\mathrm{TiO}_{\mathrm{x}}$ Nanoparticles Grown on $\mathrm{Au}(111)$ in the Water-Gas Shift Reaction, Science, 318 (2007) 17571760.

[3] K. Ding, A. Gulec, A.M. Johnson, N.M. Schweitzer, G.D. Stucky, L.D. Marks, P.C. Stair, Identification of Active Sites in CO Oxidation and Water-Gas Shift over Supported Pt Catalysts, Science, 350 (2015) 189-192.

[4] A. Martínez-Arias, D. Gamarra, M. Fernández-García, A. Hornés, P. Bera, Z. Koppány, Z. Schay, Redox-Catalytic Correlations in Oxidised Copper-Ceria CO-PROX Catalysts, Catal. Today, 143 (2009) 211-217. 
[5] Y. Ji, J.-S. Choi, T.J. Toops, M. Crocker, M. Naseri, Influence of Ceria on the $\mathrm{NO}_{\mathrm{x}}$ Storage/Reduction Behavior of Lean $\mathrm{NO}_{\mathrm{x}}$ Trap Catalysts, Catal. Today, 136 (2008) 146-155.

[6] J. Graciani, K. Mudiyanselage, F. Xu, A.E. Baber, J. Evans, S.D. Senanayake, D.J. Stacchiola, P. Liu, J. Hrbek, J.F. Sanz, J.A. Rodriguez, Highly Active Copper-Ceria and Copper-Ceria-Titania Catalysts for Methanol Synthesis from $\mathrm{CO}_{2}$, Science, 345 (2014) 546550.

[7] G. Vilé, S. Colussi, F. Krumeich, A. Trovarelli, J. Pérez-Ramírez, Opposite Face Sensitivity of $\mathrm{CeO}_{2}$ in Hydrogenation and Oxidation Catalysis, Angew. Chem. Int. Ed., 53 (2014) 12069-12072.

[8] Y. Lykhach, T. Staudt, M.P.A. Lorenz, R. Streber, A. Bayer, H.-P. Steinrück, J. Libuda, Microscopic Insights into Methane Activation and Related Processes on Pt/Ceria Model Catalysts, ChemPhysChem, 11 (2010) 1496-1504.

[9] G. Zhou, L. Barrio, S. Agnoli, S.D. Senanayake, J. Evans, A. Kubacka, M. Estrella, J.C. Hanson, A. Martínez-Arias, M. Fernández-García, J.A. Rodriguez, High Activity of $\mathrm{Ce}_{1-\mathrm{x}} \mathrm{Ni}_{\mathrm{x}} \mathrm{O}_{2-\mathrm{y}}$ for $\mathrm{H}_{2}$ Production through Ethanol Steam Reforming: Tuning Catalytic Performance through Metal-Oxide Interactions, Angew. Chem. Int. Ed., 49 (2010) 96809684.

[10] J.-D. Cafun, K.O. Kvashnina, E. Casals, V.F. Puntes, P. Glatzel, Absence of $\mathrm{Ce}^{3+}$ Sites in Chemically Active Colloidal Ceria Nanoparticles, ACS Nano, 7 (2013) 10726-10732.

[11] F. Esch, S. Fabris, L. Zhou, T. Montini, C. Africh, P. Fornasiero, G. Comelli, R. Rosei, Electron Localization Determines Defect Formation on Ceria Substrates, Science, 309 (2005) 752-755.

[12] A. Bruix, J.A. Rodriguez, P.J. Ramírez, S.D. Senanayake, J. Evans, J.B. Park, D.

Stacchiola, P. Liu, J. Hrbek, F. Illas, A New Type of Strong Metal-Support Interaction and the Production of $\mathrm{H}_{2}$ through the Transformation of Water on $\mathrm{Pt} / \mathrm{CeO}_{2}(111)$ and

$\mathrm{Pt} / \mathrm{CeO}_{\mathrm{x}} / \mathrm{TiO}_{2}$ (110) Catalysts, J. Am. Chem. Soc., 134 (2012) 8968-8974.

[13] L.J. Burcham, M. Badlani, I.E. Wachs, The Origin of the Ligand Effect in Metal Oxide Catalysts: Novel Fixed-Bed in Situ Infrared and Kinetic Studies during Methanol Oxidation, J. Catal., 203 (2001) 104-121.

[14] X.-P. Wu, X.-Q. Gong, Unique Electronic and Structural Effects in Vanadia/CeriaCatalyzed Reactions, J. Am. Chem. Soc., 137 (2015) 13228-13231.

[15] S.Y. Yao, W.Q. Xu, A.C. Johnston-Peck, F.Z. Zhao, Z.Y. Liu, S. Luo, S.D. Senanayake, A. Martinez-Arias, W.J. Liu, J.A. Rodriguez, Morphological Effects of the Nanostructured Ceria Support on the Activity and Stability of $\mathrm{CuO} / \mathrm{CeO}_{2}$ Catalysts for the Water-Gas Shift Reaction, Phys. Chem. Chem. Phys., 16 (2014) 17183-17195.

[16] S. Luo, T.-D. Nguyen-Phan, A.C. Johnston-Peck, L. Barrio, S. Sallis, D.A. Arena, S. Kundu, W. Xu, L.F.J. Piper, E.A. Stach, D.E. Polyansky, E. Fujita, J.A. Rodriguez, S.D. Senanayake, Hierarchical Heterogeneity at the $\mathrm{CeO}_{\mathrm{x}}-\mathrm{TiO}_{2}$ Interface: Electronic and Geometric Structural Influence on the Photocatalytic Activity of Oxide on Oxide Nanostructures, J. Phys. Chem. C, 119 (2015) 2669-2679. 
[17] D.J. Stacchiola, S.D. Senanayake, P. Liu, J.A. Rodriguez, Fundamental Studies of WellDefined Surfaces of Mixed-Metal Oxides: Special Properties of $\mathrm{MO}_{\mathrm{x}} / \mathrm{TiO}_{2}(110)\{\mathrm{M}=\mathrm{V}, \mathrm{Ru}$, Ce, or W\}, Chem. Rev., 113 (2013) 4373-4390.

[18] D.R. Mullins, P.V. Radulovic, S.H. Overbury, Ordered Cerium Oxide Thin Films Grown on $\mathrm{Ru}(0001)$ and Ni(111), Surf. Sci., 429 (1999) 186-198.

[19] J.L. Lu, H.J. Gao, S. Shaikhutdinov, H.J. Freund, Morphology and Defect Structure of the $\mathrm{CeO}_{2}$ (111) Films Grown on $\mathrm{Ru}(0001)$ as Studied by Scanning Tunneling Microscopy, Surf. Sci., 600 (2006) 5004-5010.

[20] N. Nilius, S.M. Kozlov, J.-F. Jerratsch, M. Baron, X. Shao, F. Viñes, S. Shaikhutdinov, K.M. Neyman, H.-J. Freund, Formation of One-Dimensional Electronic States along the Step Edges of $\mathrm{CeO}_{2}$ (111), ACS Nano, 6 (2012) 1126-1133.

[21] L. Kundakovic, D.R. Mullins, S.H. Overbury, Adsorption and Reaction of $\mathrm{H}_{2} \mathrm{O}$ and CO on Oxidized and Reduced $\mathrm{Rh} / \mathrm{CeO}_{\mathrm{x}}(111)$ Surfaces, Surf. Sci., 457 (2000) 51-62.

[22] S.H. Overbury, D.R. Mullins, D.R. Huntley, L. Kundakovic, Chemisorption and Reaction of Sulfur Dioxide with Oxidized and Reduced Ceria Surfaces, J. Phys. Chem. B, 103 (1999) 11308-11317.

[23] D.R. Mullins, S.D. Senanayake, T.L. Chen, Adsorption and Reaction of $\mathrm{C}_{1}-\mathrm{C}_{3}$ Alcohols over $\mathrm{CeO}_{\mathrm{x}}(111)$ Thin Films, J. Phys. Chem. C, 114 (2010) 17112-17119.

[24] S.M.F. Shahed, T. Hasegawa, Y. Sainoo, Y. Watanabe, N. Isomura, A. Beniya, H. Hirata, T. Komeda, STM and XPS Study of $\mathrm{CeO}_{2}(111)$ Reduction by Atomic Hydrogen, Surf. Sci., 628 (2014) 30-35.

[25] J.I. Flege, B. Kaemena, S.D. Senanayake, J. Höcker, J.T. Sadowski, J. Falta, Growth Mode and Oxidation State Analysis of Individual Cerium Oxide Islands on $\mathrm{Ru}(0001)$, Ultramicroscopy, 130 (2013) 87-93.

[26] B. Kaemena, S.D. Senanayake, A. Meyer, J.T. Sadowski, J. Falta, J.I. Flege, Growth and Morphology of Ceria on Ruthenium (0001), J. Phys. Chem. C, 117 (2013) 221-232.

[27] Y. Pan, N. Nilius, C. Stiehler, H.-J. Freund, J. Goniakowski, C. Noguera, Ceria Nanocrystals Exposing Wide (100) Facets: Structure and Polarity Compensation, Adv. Mater. Interfaces, 1 (2014).

[28] T. Duchoň, F. Dvořák, M. Aulická, V. Stetsovych, M. Vorokhta, D. Mazur, K. Veltruská, T. Skála, J. Mysliveček, I. Matolínová, V. Matolín, Comment on "Ordered Phases of Reduced Ceria as Epitaxial Films on Cu(111)", J. Phys. Chem. C, 118 (2014) 5058-5059.

[29] D.A. Chen, J.S. Ratliff, X. Hu, W.O. Gordon, S.D. Senanayake, D.R. Mullins, Dimethyl Methylphosphonate Decomposition on Fully Oxidized and Partially Reduced Ceria Thin Films, Surf. Sci., 604 (2010) 574-587.

[30] F.C. Calaza, T.L. Chen, D.R. Mullins, S.H. Overbury, Structure and Reactivity of Alkyl Ethers Adsorbed on $\mathrm{CeO}_{2}$ (111) Model Catalysts, Top. Catal., 54 (2011) 56-69. 
[31] J. Zhou, A.P. Baddorf, D.R. Mullins, S.H. Overbury, Growth and Characterization of Rh and Pd Nanoparticles on Oxidized and Reduced $\mathrm{CeO}_{\mathrm{x}}(111)$ Thin Films by Scanning Tunneling Microscopy, J. Phys. Chem. C, 112 (2008) 9336-9345.

[32] Y. Zhou, J. Zhou, Interactions of Ni Nanoparticles with Reducible $\mathrm{CeO}_{2}(111)$ Thin Films, J. Phys. Chem. C, 116 (2012) 9544-9549.

[33] S.D. Senanayake, J. Zhou, A.P. Baddorf, D.R. Mullins, The Reaction of Carbon Monoxide with Palladium Supported on Cerium Oxide Thin Films, Surf. Sci., 601 (2007) 3215-3223.

[34] Y. Pan, Y. Cui, C. Stiehler, N. Nilius, H.-J. Freund, Gold Adsorption on $\mathrm{CeO}_{2}$ Thin Films Grown on Ru(0001), J. Phys. Chem. C, 117 (2013) 21879-21885.

[35] J.I. Flege, W.X. Tang, M.S. Altman, Low-Energy Electron Microscopy, in: E.N. Kaufmann (Ed.) Characterization of Materials, John Wiley \& Sons, Inc.2012.

[36] E. Bauer, Low Energy Electron Microscopy, Rep. Prog. Phys., 57 (1994) 895.

[37] E. Bauer, Surface Microscopy with Low Energy Electrons, Springer2014.

[38] M.S. Altman, W.F. Chung, C.H. Liu, LEEM Phase Contrast, Surf. Rev. Lett., 5 (1998) 1129.

[39] A.B. Pang, T. Müller, M.S. Altman, E. Bauer, Fourier Optics of Image Formation in LEEM, J. Phys. Condens. Matter, 21 (2009) 314006.

[40] S.M. Schramm, A.B. Pang, M.S. Altman, R.M. Tromp, A Contrast Transfer Function Approach for Image Calculations in Standard and Aberration-Corrected LEEM and PEEM, Ultramicroscopy, 115 (2012) 88-108.

[41] J.I. Flege, A. Meyer, J. Falta, E.E. Krasovskii, Self-Limited Oxide Formation in Ni(111) Oxidation, Phys. Rev. B, 84 (2011) 115441.

[42] A. Locatelli, E. Bauer, Recent Advances in Chemical and Magnetic Imaging of Surfaces and Interfaces by XPEEM, J. Phys. Condens. Matter, 20 (2008) 093002.

[43] J.I. Flege, E.E. Krasovskii, Intensity-Voltage Low-Energy Electron Microscopy for Functional Materials Characterization, Phys. Status Solidi Rapid Res. Lett., 8 (2014) 463-477.

[44] R.M. Tromp, J.B. Hannon, A.W. Ellis, W. Wan, A. Berghaus, O. Schaff, A New Aberration-Corrected, Energy-Filtered LEEM/PEEM Instrument. I. Principles and Design, Ultramicroscopy, 110 (2010) 852-861.

[45] J.A. Venables, G.D.T. Spiller, M. Hanbücken, Nucleation and Growth of Thin Films, Rep. Prog. Phys., 47 (1984) 399-459.

[46] J.I. Flege, P. Sutter, Nanoscale Analysis of Ru(0001) Oxidation Using Low-Energy and Photoemission Electron Microscopy, J. Phys. Condens. Matter, 21 (2009) 314018-314018.

[47] J.-F. Jerratsch, X. Shao, N. Nilius, H.-J. Freund, C. Popa, M.V. Ganduglia-Pirovano, A.M. Burow, J. Sauer, Electron Localization in Defective Ceria Films: A Study with 
Scanning-Tunneling Microscopy and Density-Functional Theory, Phys. Rev. Lett., 106 (2011) 246801-246801.

[48] D.C. Grinter, R. Ithnin, C.L. Pang, G. Thornton, Defect Structure of Ultrathin Ceria Films on Pt(111): Atomic Views from Scanning Tunnelling Microscopy, J. Phys. Chem. C, 114 (2010) 17036-17041.

[49] C. Castellarin-Cudia, S. Surnev, G. Schneider, R. Podlicky, M.G. Ramsey, F.P. Netzer, Strain-Induced Formation of Arrays of Catalytically Active Sites at the Metal-Oxide Interface, Surf. Sci., 554 (2004) L120-L126.

[50] Y. Pan, N. Nilius, H.-J. Freund, J. Paier, C. Penschke, J. Sauer, Titration of $\mathrm{Ce}^{3+}$ Ions in the $\mathrm{CeO}_{2}$ (111) Surface by Au Adatoms, Phys. Rev. Lett., 111 (2013) 206101.

[51] S. Torbrügge, M. Reichling, A. Ishiyama, S. Morita, Ó. Custance, Evidence of Subsurface Oxygen Vacancy Ordering on Reduced $\mathrm{CeO}_{2}$ (111), Phys. Rev. Lett., 99 (2007) 56101.

[52] T. Hasegawa, S.M.F. Shahed, Y. Sainoo, A. Beniya, N. Isomura, Y. Watanabe, T. Komeda, Epitaxial Growth of $\mathrm{CeO}_{2}(111)$ Film on $\mathrm{Ru}(0001)$ : Scanning Tunneling Microscopy (STM) and X-Ray Photoemission Spectroscopy (XPS) Study, J. Chem. Phys., 140 (2014) 044711.

[53] S. Fölsch, U. Barjenbruch, M. Henzler, Atomically Thin Epitaxial Films of $\mathrm{NaCl}$ on Germanium, Thin Solid Films, 172 (1989) 123-132.

[54] C. Schwennicke, J. Schimmelpfennig, H. Pfnür, Morphology of Thin NaCl Films Grown Epitaxially on Ge(100), Surf. Sci., 293 (1993) 57-66.

[55] P.W. Sutter, J.-I. Flege, E.A. Sutter, Epitaxial Graphene on Ruthenium, Nat. Mater., 7 (2008) 406-411.

[56] E. Sutter, P. Albrecht, F.E. Camino, P. Sutter, Monolayer Graphene as Ultimate Chemical Passivation Layer for Arbitrarily Shaped Metal Surfaces, Carbon, 48 (2010) 44144420 .

[57] E. Sutter, P. Albrecht, P. Sutter, Graphene Growth on Polycrystalline Ru Thin Films, Appl. Phys. Lett., 95 (2009) 133109.

[58] D.R. Mullins, S.H. Overbury, D.R. Huntley, Electron Spectroscopy of Single Crystal and Polycrystalline Cerium Oxide Surfaces, Surf. Sci., 409 (1998) 307-319.

[59] M. Baron, O. Bondarchuk, D. Stacchiola, S. Shaikhutdinov, H.J. Freund, Interaction of Gold with Cerium Oxide Supports: $\mathrm{CeO}_{2}(111)$ Thin Films vs $\mathrm{CeO}_{\mathrm{x}}$ Nanoparticles, J. Phys. Chem. C, 113 (2009) 6042-6049.

[60] J.I. Flege, B. Kaemena, A. Meyer, J. Falta, S.D. Senanayake, J.T. Sadowski, R.D. Eithiraj, E.E. Krasovskii, Origin of Chemical Contrast in Low-Energy Electron Reflectivity of Correlated Multivalent Oxides: The Case of Ceria, Phys. Rev. B, 88 (2013) 235428.

[61] J. Höcker, T.O. Menteş, A. Sala, A. Locatelli, T. Schmidt, J. Falta, S.D. Senanayake, J.I. Flege, Unraveling the Dynamic Nanoscale Reducibility $\left(\mathrm{Ce}^{4+} \rightarrow \mathrm{Ce}^{3+}\right)$ of $\mathrm{CeO}_{\mathrm{x}}-\mathrm{Ru}$ in Hydrogen Activation, Adv. Mater. Interfaces, (2015) 1500314-1500314. 
[62] S. Alayoglu, K. An, G. Melaet, S. Chen, F. Bernardi, L.W. Wang, A.E. Lindeman, N. Musselwhite, J. Guo, Z. Liu, M.A. Marcus, G.A. Somorjai, Pt-Mediated Reversible Reduction and Expansion of $\mathrm{CeO}_{2}$ in Pt Nanoparticle/Mesoporous $\mathrm{CeO}_{2}$ Catalyst: In Situ X-ray Spectroscopy and Diffraction Studies under Redox $\left(\mathrm{H}_{2}\right.$ and $\left.\mathrm{O}_{2}\right)$ Atmospheres, J. Phys. Chem. C, 117 (2013) 26608-26616.

[63] C.L. Dong, A. Augustsson, C.L. Chen, C.L. Chang, Y.Y. Chen, J.H. Guo, Electronic Structure and Valence State of $\mathrm{CeAl}_{2}$ from X-Ray Absorption and Emission Spectroscopy, J. Electron Spectrosc. Relat. Phenom., 144-147 (2005) 581-584.

[64] H.-T. Chen, Y.M. Choi, M. Liu, M.C. Lin, A Theoretical Study of Surface Reduction Mechanisms of $\mathrm{CeO}_{2}(111)$ and (110) by $\mathrm{H}_{2}$, ChemPhysChem, 8 (2007) 849--855.

[65] D. Fernández-Torre, J. Carrasco, M.V. Ganduglia-Pirovano, R. Pérez, Hydrogen Activation, Diffusion, and Clustering on $\mathrm{CeO}_{2}(111)$ : A DFT+U Study, J. Chem. Phys., 141 (2014) 14703.

[66] M. García-Melchor, N. López, Homolytic Products from Heterolytic Paths in $\mathrm{H}_{2}$ Dissociation on Metal Oxides: The Example of $\mathrm{CeO}_{2}$, J. Phys. Chem. C, 118 (2014) 1092110926.

[67] V. Stetsovych, F. Pagliuca, F. Dvořák, T. Duchoň, M. Vorokhta, M. Aulická, J. Lachnitt, S. Schernich, I. Matolínová, K. Veltruská, T. Skála, D. Mazur, J. Mysliveček, J. Libuda, V. Matolín, Epitaxial Cubic $\mathrm{Ce}_{2} \mathrm{O}_{3}$ Films via $\mathrm{Ce}-\mathrm{CeO}_{2}$ Interfacial Reaction, J. Phys. Chem. Lett., 4 (2013) 866-871.

[68] T. Duchoň, F. Dvořák, M. Aulická, V. Stetsovych, M. Vorokhta, D. Mazur, K. Veltruská, T. Skála, J. Mysliveček, I. Matolínová, V. Matolín, Ordered Phases of Reduced Ceria As Epitaxial Films on $\mathrm{Cu}(111)$, J. Phys. Chem. C, 118 (2014) 357-365.

[69] J.I. Flege, J. Hrbek, P. Sutter, Structural Imaging of Surface Oxidation and Oxidation Catalysis on Ru(0001), Phys. Rev. B, 78 (2008) 165407.

[70] J.I. Flege, J. Lachnitt, D. Mazur, P. Sutter, J. Falta, Role of $\mathrm{RuO}_{2}(100)$ in Surface Oxidation and CO Oxidation Catalysis on Ru(0001), Phys. Chem. Chem. Phys., 18 (2016) 213-219.

[71] J.I. Flege, B. Herd, J. Goritzka, H. Over, E.E. Krasovskii, J. Falta, Nanoscale Origin of Mesoscale Roughening: Real-Time Tracking and Identification of Three Distinct Ruthenium Oxide Phases in Ruthenium Oxidation, ACS Nano, (2015).

[72] E.E. Krasovskii, J. Höcker, J. Falta, J.I. Flege, Surface Resonances in Electron Reflection from Overlayers, J. Phys. Condens. Matter, 27 (2015) 35501. 
Graphical Abstract:
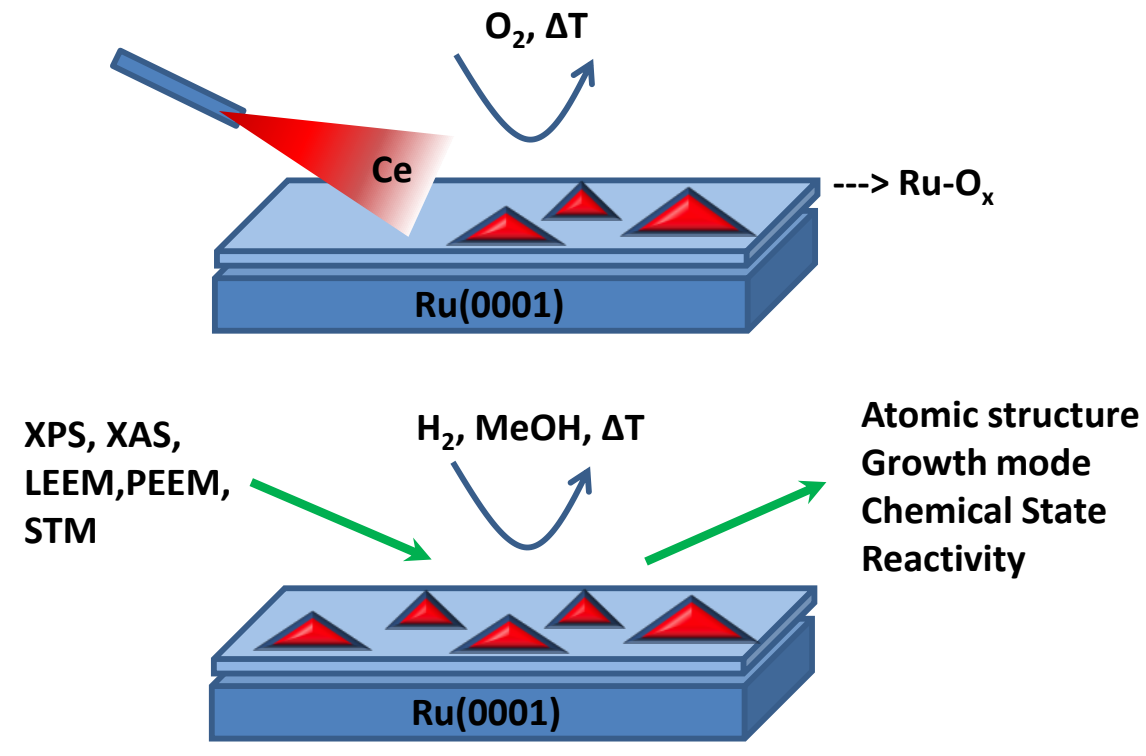